1 Chasing the metabolism of novel syntrophic acetate-oxidizing bacteria in

\title{
2 thermophilic methanogenic chemostats
}

4 Yan Zeng a, Dan Zheng ${ }^{\mathrm{b}}$, Min Gou ${ }^{\mathrm{c}}$, Zi-Yuan Xia ${ }^{\mathrm{c}}$, Ya-Ting Chen ${ }^{\mathrm{c}, \mathrm{d}^{*}}$, Masaru Konishi

$5 \quad \mathrm{Nobu}^{\mathrm{e}, *}$, Yue-Qin Tang ${ }^{\mathrm{a}, \mathrm{c}, *}$

6

7 a Institute of New Energy and Low-carbon Technology, Sichuan University, No. 24,

8 South Section 1, First Ring Road, Chengdu, Sichuan 610065, China

$9 \quad{ }^{b}$ Biogas Institute of Ministry of Agriculture and Rural Affairs, Section 4-13, Renmin

10 Road South, Chengdu 610041, P. R. China

$11{ }^{\mathrm{c}}$ College of Architecture and Environment, Sichuan University, No. 24, South Section

12 1, First Ring Road, Chengdu, Sichuan 610065, China

$13{ }^{\mathrm{d}}$ Institute for Disaster Management and Reconstruction, Sichuan University-Hong

14 Kong Polytechnic University, Chengdu, Sichuan 610207, China

$15{ }^{\mathrm{e}}$ Bioproduction Research Institute, National Institute of Advanced Industrial Science 16 and Technology (AIST), Central 6, Higashi 1-1-1, Tsukuba, Ibaraki 305-8566, Japan

18 *Correspondence: Ya-Ting Chen, Institute for Disaster Management and 19 Reconstruction, Sichuan University-Hong Kong Polytechnic University, Chengdu, 20 Sichuan 610207, China

21 and Masaru Konishi Nobu, Bioproduction Research Institute, National Institute of 22 Advanced Industrial Science and Technology (AIST), Central 6, Higashi 1-1-1, 23 Tsukuba, Ibaraki 305-8566, Japan

24 and Yue-Qin Tang, College of Architecture and Environment, Sichuan University, No. 25 24, South Section 1, First Ring Road, Chengdu, Sichuan 610065, China 
bioRxiv preprint doi: https://doi.org/10.1101/2021.07.06.451242; this version posted July 6, 2021. The copyright holder for this preprint (which was not certified by peer review) is the author/funder, who has granted bioRxiv a license to display the preprint in perpetuity. It is made available under aCC-BY-NC-ND 4.0 International license.

26 Tel. (fax): +86 2885990936

27 E-mail: cytscu1101@scu.edu.cn and m.nobu@aist.go.jp and tangyq@ scu.edu.cn 


\section{Abstract}

Background: Acetate is the major intermediate of anaerobic digestion of organic waste to $\mathrm{CH}_{4}$. In anaerobic methanogenic systems, acetate degradation is carried out by either acetoclastic methanogenesis or a syntrophic degradation by a syntrophy of acetate oxidizers and hydrogenotrophic methanogens. Due to challenges in isolation of syntrophic acetate-oxidizing bacteria (SAOB), the diversity and metabolism of SAOB, as well as the mechanisms of their interactions with methanogenic partners remain poorly understood.

Results: In this study, we successfully enriched previously unknown SAOB by operating continuous thermophilic anaerobic chemostats fed with acetate, propionate, butyrate, or isovalerate as the sole carbon and energy source. They represent novel clades belonging to Clostridia, Thermoanaerobacteraceae, Anaerolineae, and Gemmatimonadetes. In these SAOB, acetate is degraded through reverse WoodLjungdahl pathway or an alternative pathway mediated by the glycine cleavage system, while the SAOB possessing the latter pathway dominated the bacterial community. Moreover, $\mathrm{H}_{2}$ is the major product of the acetate degradation by these SAOB, which is mediated by $[\mathrm{FeFe}]$-type electron-confurcating hydrogenases, formate dehydrogenases, and NADPH reoxidation complexes. We also identified the methanogen partner of these SAOB in acetate-fed chemostat, Methanosarcina thermophila, which highly expressed genes for $\mathrm{CO}_{2}$-reducing methanogenesis and hydrogenases to supportively consuming $\mathrm{H}_{2}$ at transcriptional level. Finally, our bioinformatical analyses further suggested that these previously unknown syntrophic lineages were prevalent and might play critical 
50 roles in thermophilic methanogenic reactors.

51 Conclusion: This study expands our understanding on the phylogenetic diversity and

52 in situ biological functions of uncultured syntrophic acetate degraders, and presents

53 novel insights on how they interact with their methanogens partner. These knowledges

54 strengthen our awareness on the important role of SAO in thermophilic methanogenesis

55 and may be applied to manage microbial community to improve the performance and

56 efficiency of anaerobic digestion.

57 Keywords: Thermophilic anaerobic digestion, Microbial community, Syntrophic 58 acetate oxidation, Glycine cleavage, Energy conservation

\section{Background}

Anaerobic digestion (AD) of organic waste to produce methane offers opportunities to deliver multiple environmental benefits as it encompasses organic waste treatment and renewable energy production. Volatile fatty acids (VFAs) are the main intermediates, and thus syntrophic fatty acid oxidation is thought to be the key step in AD [1]. Notably, acetate serves as the most important intermediate metabolite and the major precursor of methane, accounting for 60 to $80 \%$ of methane production in anaerobic digesters $[2,3]$. Notably, metabolic disorders would lead to accumulation of acetate in anaerobic digesters, which may cause acidification and reduce methane

69 production, destabilizing the AD systems. Therefore, uncovering the underly 70 mechanism of anaerobic acetate metabolism is fundamental to manage microbial AD 71 system for better performance. 

with hydrogenotrophic methanogenesis (Eqs. 2 and 3) [4].

$$
\begin{array}{ll}
\mathrm{CH}_{3} \mathrm{COO}^{-}+\mathrm{H}_{2} \mathrm{O} \rightarrow \mathrm{CH}_{4}+\mathrm{HCO}_{3}^{-} & \Delta G^{0^{\prime}}=-31.0 \mathrm{~kJ} \mathrm{~mol}^{-1} \\
\mathrm{CH}_{3} \mathrm{COO}^{-}+4 \mathrm{H}_{2} \mathrm{O} \rightarrow 2 \mathrm{HCO}_{3}^{-}+4 \mathrm{H}_{2}+\mathrm{H}^{+} & \Delta G^{0^{\prime}}=+104.6 \mathrm{~kJ} \mathrm{~mol}^{-1} \\
4 \mathrm{H}_{2}+\mathrm{HCO}_{3}^{-}+\mathrm{H}^{+} \rightarrow \mathrm{CH}_{4}+3 \mathrm{H}_{2} \mathrm{O} & \Delta G^{0^{\prime}}=-135.6 \mathrm{~kJ} \mathrm{~mol}^{-1}
\end{array}
$$

In the former route, acetate is cleaved into carbonyl group and methyl group, then respectively oxidized to $\mathrm{CO}_{2}$ and reduced to $\mathrm{CH}_{4}$ by aceticlastic methanogens Methanosarcina or Methanothrix [5]. In the latter route, both methyl and carbonyl group of acetate are oxidized to $\mathrm{CO}_{2}$, associated with the generation of $\mathrm{H}_{2}$. This reaction is thermodynamically unfavorable under standard conditions $\left(\Delta \mathrm{G}^{0^{\prime}}=+104.6 \mathrm{~kJ} \mathrm{~mol}^{-1}\right)$. Thus, "syntrophic" cooperation with hydrogen-scavenging methanogenic partners $\left(\Delta \mathrm{G}^{0^{\prime}}=-135.6 \mathrm{~kJ} \mathrm{~mol}^{-1}\right)$ is necessary to maintain thermodynamic favorability $[4,6]$. Previous studies report observation of syntrophic acetate oxidation in selective conditions (e.g., high concentration of ammonia [7], high temperature [8], or low loading rate and long retention time [9]), suggesting that this niche may play an critical role in diverse methanogenic systems that may have challenges in supporting aceticlastic methanogens.

Although six strains of syntrophic acetate-oxidizing bacteria (SAOB) have been

91 cultured, the full diversity and metabolism of SAOB still remain poorly understood.

92 Among described SAOB, while three species (Thermacetogenium phaeum [10], 93 Syntrophaceticus schinkii [11], and Tepidanaerobacter acetatoxydans [12]) possess the 
94 well-known reverse Wood-Ljungdahl (WL) pathway for syntrophic acetate oxidation

95 [13, 14], but two (Pseudothermotoga lettingae [15] and Schunerera ultunensis,

96 previously Clostridium ultunense [16]) lack genes for this classical WL pathway and

97 are suspected to possess an alternative metabolism, potentially mediated by a glycine

98 cleavage system pathway $[13,17]$. Moreover, these cultured SAOB are generally

99 detected with low abundances in anaerobic bioreactors [18-21]. Previous studies based

100 on DNA or protein stable isotope probing (SIP) point towards the presence of other

101 phylogenetically distinct uncultured acetate oxidizers in anaerobic digestors [22-24].

102 Therefore, uncovering the diversity, ecology, metabolism, and symbiotic interactions

103 of these yet-to-be cultured SAOB is essential for improving our understanding and

104 operation of methanogenic bioreactors under stressed conditions.

Furthermore, it is also crucial for understanding the mechanisms of the

106 syntrophic interaction between SAOB and their methanogens partner. Interspecies

107 electron transfer between these two groups is essential to maintain thermodynamic

108 favorability of microbial methanogenesis [25, 26]. Previous survey on syntrophic

109 acetate metabolizers suggested that $\mathrm{H}_{2}$ has been regarded as electron carrier from

110 acetate oxidizers to methanogens $[4,14,27]$. Several recent studies also suggested that

111 formate transfer also play a role in propionate [28,29] and isovalerate [30] syntrophic

112 degradation. Direct interspecies electron transfer (DIET) activity has been suggested in

113 enrichment communities degrading propionate and butyrate [31, 32]. However,

114 whether formate transfer and DIET transfer play roles in acetate syntrophic degradation

115 is not yet known. 
116 One effective cultivation-independent approach to studying the physiology and in

117 situ metabolism of uncultured organisms is the combination of metagenomics and

118 metatranscriptomics $[17,30,33,34]$. In this study, we employed such approach to

119 recover genomes (metagenome-assembled genomes, MAGs) and gene expression

120 profiles of novel potential acetate degraders from fatty-acid-fed thermophilic anaerobic

121 chemostats to investigate their catabolic pathways, energy conservation, and metabolic

122 interactions with their methanogens partner.

\section{Results and discussions}

\section{Chemostat operation and performance}

126 Eight thermophilic anaerobic chemostats were stably operated with synthetic 127 wastewater containing acetate, propionate, butyrate, or isovalerate as the sole carbon 128 and energy source at different loading rates (Table S1; Materials and Methods). During 129 the steady operation period, the performance of chemostats was stable, i.e., biogas 130 production was stable and concentrations of VFAs in the eight chemostats were 131 markedly low (10 30 $\left.\mathrm{mg} \mathrm{L}^{-1}\right)$, indicating that VFAs fed were almost completely 132 degraded by these microbial communities (Table 1 and Fig. S1).

134 Microbial diversity and community composition of thermophilic anaerobic 135 chemostats

136 Based on DNA- and RNA-based 16S ribosomal RNA gene analysis, the bacterial 137 community of the thermophilic chemostats contain diverse population belonging to 138 uncultured lineages (Figs. 1 and S2). The dominated bacterial populations included 139 Firmicutes (e.g., order MBA03 and family Thermoanaerobacteraceae), Bacteroidetes 
140 (Lentimicrobiaceae), and Chloroflexi (Anaerolineaceae), which were at high abundance

141 (up to $72 \%$ ) and activity (up to 41\%) in the all the thermophilic chemostats.

142 Thermodesulfovibrio displayed low DNA-based relative abundance, but also high

143 activity (up to $18 \%$ of transcriptome). Notably, one genus associated with previously

144 isolated syntrophic acetate-oxidizing bacteria (SAOB) (Tepidanaerobacter; [12]) was

145 detected but only comprised less than $1 \%$ of the total bacterial community.

146 In regarding to archaeal community, according to 16S rRNA gene analysis,

147 Methanosarcina whose relative abundance accounted for $26 \%$ 94\% and 48\% 99\% of

148 archaeal community at the DNA and RNA level, respectively, was the active

149 methanogen across all the thermophilic chemostats. Methanosarcina OTUs held a $99.5 \%$

150 sequence similarity to multitrophic methanogen Methanosarcina thermophila TM-1,

151 which is able to turnout $\mathrm{H}_{2}$ /formate, acetate, methanol to methane [35].

152 Methanothermobacter was dominant in PTL (67\%-DNA, 51\%-RNA), PTH (47\%-

153 DNA, 42\%-RNA), and BTL (25\%-DNA, 24\%-RNA), while Methanoculleus

154 predominated in BTH (33\%-DNA, 29\%-RNA) and VTH (59\%-DNA, 9\%-RNA) (Fig.

155 S4).

156 To profile the metabolic capability of such bacteria and methanogens (potential

157 partners and competitors), a total of 173 Gbp metagenomic clean sequences (ATL, 35

158 Gbp; PTL, 69 Gbp; BTL, 34 Gbp; VTL, 35 Gbp) were obtained. Illumina paired-end

159 reads from the two subsamples (three subsamples in PTL) were co-assembled. Binning

160 the assembled contigs of metagenomes for thermophilic communities yielded 108, 157,

16181 and 96 MAGs from ATL, PTL, BTL, and VTL, respectively. To obtain gene

162 expression profiles of the bacteria and archaea in the chemostats, a total of 287 million

163 metatranscriptomic reads (33.6 Gbp, approximately $4.2 \mathrm{Gbp}$ for each RNA sample) 
164 were sequenced and mapped to the MAGs for each chemostat (78-95\% of reads

165 mapped using a 100\% nucleotide similarity cutoff). Based on mapping metagenomic

166 reads to the obtained MAGs, the bacterial populations retrieved accounted for $79 \%$,

$16752 \%, 67 \%$ and $67 \%$ of the metagenomic reads obtained from ATL, PTL, BTL and VTL

168 (Fig. S3C). In addition, these bacterial populations accounted for $80 \%, 74 \%, 65 \%$ and

$16973 \%$ of the metatranscriptomic reads from ATL, PTL, BTL and VTL, respectively (Fig.

170 S3D).

As for the methanogen archaea, Methanosarcina thermophila (MAG.ATL014)

172 was the active methanogen in ATL, PTL, BTL and VTL, accounting for $18 \%, 11 \%, 3 \%$

173 and $15 \%$ of the metatranscriptomic reads from PTL, BTL and VTL, respectively (Fig.

174 S5 and Table S2). The activity of hydrogenotrophic methanogens was negligible in

175 ATL. Methanothermobacter (MAG.PTL002) was dominant accounting for $13 \%$ of the

176 metatranscriptomic reads in PTL. Methanoculleus (MAG.BTL076 and MAG.VTL077)

177 predominated in BTL and VTL, accounting for $28 \%$ and $8 \%$ of the metatranscriptomic

178 reads from BTL and VTL, respectively.

179

180 Syntrophic metabolism and energy conservation of acetate-degrading community

\section{1 in ATL}

182 In the analysis of community structure based on 16S rRNA gene sequencing, the

183 relative abundance and RNA-based activity of bacteria was greater than that of archaea

184 in the all the eight chemostats (Fig. S3A and S3B). This phenomenon was also observed

185 in the analysis based on metagenome and metatranscriptome data (Fig. S3C and S3D). 
186 In methanogenic system, syntrophic fatty acid oxidizers convert propionate, butyrate,

187 and isovalerate to acetate and $\mathrm{H}_{2}$ /formate, and symbiotically hand off these by-products

188 to partnering acetate- and $\mathrm{H}_{2}$-consuming methanogenic archaea $[23,28,30]$. Therefore,

189 it was expected that bacteria displayed high abundance and activity in propionate-,

190 butyrate-, and isovalerate-fed chemostats, which is consistent with our observation. In

191 acetate-fed chemostats, since aceticlastic methanogens, such as Methanosarcina, could

192 autonomously degraded acetate, they were expected to dominate the methanogenic

193 communities. However, despite that Methanosarcina (99.5\% rRNA sequence similarity

194 to M. thermophila TM-1; MAG: MAG.ATL014) held a considerably high abundance

195 and activity in our acetate-fed chemostats, the community are unexpectedly dominated

196 by bacterial populations. This result suggested that several bacterial populations may

197 play a significant role in acetate degradation in our acetate-fed chemostats, and

198 potentially be the previously unknown SAOB clades that we were looking for.

\section{High activity of $\mathrm{CO}_{2}$-reducing methanogenesis in Methanosarcina}

Although Methanosarcina groups were previously reported as the main

204 produced metabolites (e.g., $\mathrm{H}_{2}$ and $\mathrm{CO}_{2}$ ) to produce methane in our acetate-fed 205 chemostats, playing a role as the partner of the potential SAOB in the community. To 206 test this hypothesis, we first analyzed the metabolic feature of the Methanosarcina 207 MAGs in ATL. In accordance with our hypothesis, the dominant Methanosarcina 208 MAG.ATL014 interestingly expressed genes for $\mathrm{CO}_{2}$ reduction (in addition to acetate 
catabolism; top octile and quartile of expressed genes in the corresponding MAG respectively; Figs. 2 and 3B; Table S3) even though Methanosarcina sp. are known to

211 significantly downregulate expression of such genes during acetate degradation as they

212 are not necessary $[36,37]$. Decrease in the activity of the $\mathrm{CO}_{2}$-reducing pathway also

213 results in decreased cellular concentrations (up to 10 -fold) of coenzyme $\mathrm{F}_{420}$, an 214 electron carrier for the $\mathrm{CO}_{2}$ branch during growth on acetate [38], and, though 215 qualitative, Methanosarcina-like cells showed higher autofluorescence (at $420 \mathrm{~nm}$ ) in 216 chemostats where Methanosarcina highly expressed the $\mathrm{CO}_{2}$-reducing pathway (i.e., 217 ATL and ATH compared to PTL in Fig. S6; [28]). Thus, the Methanosarcina in situ 218 likely utilizes an alternative electron source in parallel with acetate.

219 Given the lack of exogenous $\mathrm{H}_{2}$ and methylated compounds (i.e., compounds that 220 would stimulate usage of the $\mathrm{CO}_{2}$-reducing branch), this may indicate the presence of 221 some bacterial populations in the chemostat catabolizing acetate and syntrophically 222 transferring $\mathrm{H}_{2}$ and/or electrons to Methanosarcina. Supporting this, (i) acetate223 degrading $M$. thermophila cells are known to consume $\mathrm{H}_{2}$ with affinity similar to that 224 of hydrogenotrophic methanogens [39] and (ii) Methanosarcina MAG.ATL014 highly 225 expressed hydrogenases (Fig. 3B; Table S4). This is consistent with previous studies 226 that Methanosarcina had been observed together with SAOB in acetate-fed 227 thermophilic anaerobic digesters [22, 40]. Moreover, the detection of $\mathrm{H}_{2}$-utilizing 228 methanogens (Methanothermobacter MAG.ATL045 and Methanomassiliicoccus 229 MAG.ATL089; albeit at much lower activity levels) also suggests that $\mathrm{H}_{2}$ transfer is 230 taking place in situ (Figs. 2 and 3B; Table S3). The parallel expression of methanol231 reducing methanogenesis by Methanomassiliicoccus and methyl compound 232 metabolism by Methanosarcina suggests that Methanosarcina may generate methanol 233 (methanol:coenzyme M methytransferase has been shown to generate methanol in vitro 
234 barkeri [41]) and feed into Methanomassiliicoccus methanogenesis.

\section{Putative syntrophic acetate metabolizers}

To identify potential uncultured SAOB that may interact with the above methanogens, we performed metabolic reconstruction of the MAGs recovered for

239 abundant and active bacterial populations. Genome- and transcriptome-based 240 prediction of $\mathrm{SAOB}$ is challenging given that the conventional acetate oxidation 241 pathway (reverse WL pathway) and the previously proposed glycine-mediated 242 alternative pathway can be used for carbon fixation and serine/glycine biosynthesis 243 respectively. To identify genotypic features associated with SAOB, we performed 244 comparative genomics of isolated SAOB. All isolated SAOB that possess the reverse 245 WL pathway conserve NAD(P) transhydrogenase, while organisms only capable of 246 homoacetogenesis do not encode genes for this enzyme. Both SAOB (S. ultunensis and 247 P. lettingae) that lack the WL pathway possess NADPH re-oxidizing complexes, albeit 248 different enzymes: NADPH-dependent FeFe hydrogenase (S. ultunensis) and NADH249 dependent NADP:ferredoxin oxidoreductase (P. lettingae). P. lettingae has previously 250 been proposed to use a glycine dehydrogenase-mediated pathway for C1 metabolism 251 and S. ultunensis may also use this pathway as it lacks the conventional reverse WL 252 pathway. Interestingly, S. ultunensis encodes the glycine dehydrogenase directly 253 upstream of NADPH-dependent FeFe hydrogenase, suggesting potential association of 254 glycine metabolism, NADPH reoxidation, and $\mathrm{H}_{2}$ generation. Thus, we restricted our 255 analysis to populations encoding and highly expressing the WL pathway or glycine256 mediated pathway along with $\mathrm{NADPH}$ re-oxidation and $\mathrm{H}_{2} /$ formate generation 257 (expression in top quartile of each population's expression profile). To further increase 258 the stringency of our analysis, we further exclude any populations that highly express 
259 amino acid catabolism (which is often NADP-dependent) using expression of glutamate

260 dehydrogenase as a marker (i.e., gdhA/gdhB in top quartile of expression profile).

261 We identified bacterial populations associated with uncultured Clostridia

262 (MAG.ATL040, MAG.ATL011, MAG.ATL033, and MAG.ATL044),

263 Thermoanaerobacteraceae (MAG.ATL024, MAG.ATL090, and MAG.ATL105),

264 Anaerolineae (MAG.ATL001 and MAG.ATL101) and Gemmatimonadetes

265 (MAG.ATL080) as the potential SAOB that encode the reverse WL and glycine-

266 mediated acetate-oxidizing pathways and complementary NADPH re-oxidation and

$267 \mathrm{H}_{2}$ /formate-generating enzymes (Figs. 2 and S7; Tables S5 and S6) [17, 42].

268 Phylogenetic analysis revealed that these bacterial populations were distantly related to

269 known SAOB (Fig.4). Furthermore, the Clostridia members (MAG.ATL011,

270 MAG.ATL033, and MAG.ATL044) and Thermoanaerobacteraceae members

271 (MAG.ATL024, MAG.ATL090, and MAG.ATL105) were phylogenetically closely

272 related to each other, but distantly related to any cultured organisms (Fig.4). Based on

273 the above criteria, among these populations, Thermoanaerobacteraceae population

274 (MAG.ATL105), Anaerolineae populations (MAG.ATL001 and MAG.ATL101) and

275 Clostridia population (MAG.ATL040) may syntrophically degrade acetate via reverse

276 Wood-Ljungdahl pathway. Thermoanaerobacteraceae population (MAG.ATL024 and

277 MAG.ATL090), Clostridia population (MAG.ATL044) and Gemmatimonadetes

278 (MAG.ATL080) may syntrophically degrade acetate via Thermotogae-associated

279 pathway; Figs. 2 and 3A; Tables S5 and S6). These results suggested that previously

280 unknown bacterial clades plays a critical role in syntrophic acetate oxidation.

282 Energy conservation and electron flow in acetate oxidizers

283 Metabolism under methanogenic conditions necessitates complementation of 
284 substrate oxidation with electron balance. Thus, we explored energy conservation

285 systems (e.g., electron transfer and electron confurcation/bifurcation) of the putative

286 acetate oxidizers. Most of the putative SAOB encode cytoplasmic [FeFe]-type electron-

287 confurcating hydrogenases (HydABC) (Figs. 3A and 5; Table S6) that use exergonic

288 oxidation of reduced ferredoxin $\left(\mathrm{Fd}_{\mathrm{red}}\right)\left(\mathrm{E}^{0^{\prime}}=-430 \mathrm{mV}\right)$ to drive unfavorable $\mathrm{H}_{2}$ 289 generation from NADH oxidation $\left(\mathrm{E}^{0^{\prime}}=-230 \mathrm{mV}\right)$ [43], a energy conservation strategy

290 associated with syntrophic fatty acid oxidizers [14, 29, 44]. In addition, populations

291 (MAG.ATL080 and MAG.ATL090) performed $\mathrm{H}_{2}$ generation via the NADPH292 dependent [FeFe] hydrogenase (HndABCD) (Figs. 3A and 5; Table S6). The 293 Anaerolineae member (MAG.ATL001) also encodes a cytochrome b-linked NiFe 294 hydrogenase (HybABCO) and a cytosolic NiFe hydrogenase (HoxEFUHY) (Figs. 3A 295 and 5; Table S6). As for formate metabolism, six of eight SAOB MAGs possess a 296 ferredoxin-dependent formate dehydrogenase (FdhH). The Clostridia-related member 297 MAG.ATL044, Thermoanaerobacteraceae (MAG.ATL105), and Anaerolineae 298 (MAG.ATL001) highly expressed a putative NADPH-dependent formate 299 dehydrogenases (FdpAB). MAG.ATL044 harbors a putative NAD ${ }^{+}$-dependent 300 electron-bifurcating complex (FdhA-hydBC: formate dehydrogenase organized with 301 HydBC-related subunits) (Figs. 3A and 5; Table S6). Therefore, the putative SAOB 302 identified encode and express enzymes for energy conservation and electron flow that 303 support thermodynamically challenging catabolism and syntrophy.

304 As discussed above, reducing equivalents (i.e., NADH, NADPH and reduced 305 ferredoxin $\left.\left[\mathrm{Fd}_{\mathrm{red}}\right]\right)$ involve in the actions of hydrogenases and formate dehydrogenases. 
306 Acetate oxidation via reverse WL pathway and glycine-mediated pathway generate

307 both NADH and NADPH, and the latter pathway yields one mol of ATP per mol acetate

308 oxidized (Fig. 2A) [17, 45]. However, $\mathrm{Fd}_{\text {red }}$ is not directly generated from acetate

309 degradation. To complete acetate degradation, SAOB in acetate-degrading community

310 encode redox complexes supporting electron transfer between (i) NAD(H) and Fd

311 (Rhodobacter nitrogen fixation complex Rnf; NADH:Fd oxidoreductase;

312 MAG.ATL080, MAG.ATL024, MAG.ATL044, MAG.ATL090, MAG.ATL105 and

313 MAG.ATL040) [46], (ii) NADP(H) and NAD(H) and Fd (NADH-dependent NADP:Fd

314 oxidoreductase NfnAB; MAG.ATL024, MAG.ATL090, MAG.ATL105,

315 MAG.ATL040, MAG.ATL001 and MAG.ATL101) [17, 43, 47], (iii) NAD(H) and

316 NADP(H) (transhydrogenase PntAB; MAG.ATL080, MAG.ATL024, MAG.ATL044

317 and MAG.ATL090) [48, 49], (iv) Fd and unknown electron carriers (uncharacterized

318 oxidoreductase Flox:Hdr; MAG.ATL090, MAG.ATL105 and MAG.ATL101) [17, 45,

319 50] (Figs. 3A and 5; Table S6). Using these complexes, the syntrophic acetate oxidizers

320 may employ reverse electron transport and electron bifurcation to generate $\mathrm{H}_{2}$.

321 In addition, we found that MAG.ATL044 contained a more energy-efficient

322 pathway, which might be the reason why it possessed high abundance and activity in

323 ATL (Figs. 3A and 5; Table S6). Analyses of metatranscriptomic indicates that

324 MAG.ATL044 did not express $\mathrm{H}_{2}$ generation activity, suggesting it converted acetate

325 to formate but not further to $\mathrm{H}_{2}$ and $\mathrm{CO}_{2}$ (Figs. 3A and 5; Table S6). This observation

326 is consistent with previous study that some novel acetate-degrading species expressing

327 the glycine-mediated pathway just oxidized acetate to formate (no $\mathrm{H}_{2}$ generation) in 
328 full-scale anaerobic digesters [51]. Formate was not detected in ATL, indicating that

329 acetate was completely oxidized without accumulation of this metabolic intermediate.

330 In addition, we did not detect $\mathrm{F}_{420}$-reducing formate oxidation (FdhAB) in

331 Methanosarcina in ATL. Thus, we suspected other syntrophic species may convert the

332 acetate-derived formate to $\mathrm{H}_{2}$. In agreement, metagenomics analyses showed that

333 Clostridia (MAG.ATL106) and Anaerolineaceae (MAG.ATL019) highly expressed

334 formate dehydrogenases and hydrogenases (Fig. 5 and Table S6), suggesting potential

335 involvement in formate oxidation $[52,53]$. In contrast, another acetate degrader

336 MAG.ATL001, which was the second most active bacterial MAG (accounting for 13.1\%

337 of the activity) highly expressed formate dehydrogenases and hydrogenase at similar

338 levels, oxidizing acetate to $\mathrm{H}_{2}$ and $\mathrm{CO}_{2}$ via reverse WL pathway (Figs. 3A and 5; Table

339 S6). This result suggests that acetate oxidation by MAG.ATL001 may prefer $\mathrm{H}_{2}$ for

340 interspecies electron transfer in our thermophilic community. The glycine-mediated

341 pathway avoids endergonic 5-methyl-THF oxidation, generating a yield of 1 ATP per

342 acetate. In comparison, the reverse WL pathway hold a puzzling theoretical yield of 0

343 ATP per acetate [17] (Fig. 2A). This optimal energy generation strategy might partially

344 explain the high abundance and activity of MAG.ATL044.

345 In order to improve our understanding of energy conservation revolving around

346 SAO process, we compared electron transfer mechanisms of our novel enriched acetate

347 oxidizers with previously known SAOB. We found a new formate dehydrogenase,

348 FdpAB, located in the novel acetate oxidizers in ATL (Figs. 3A and S8; Tables S6 and

349 S7). T. phaeum and S. schinkii encode membrane-bound cytochrome b-linked quinone- 
350 dependent formate dehydrogenase (FdnGHI) associated with proton extrusion, which

351 were not found in novel acetate oxidizers in ATL. In addition, all the known groups of

352 formate dehydrogenases were not identified in T. acetatoxydans and P. lettingae,

353 though they were capable of converting acetate into $\mathrm{CO}_{2}$ and $\mathrm{H}_{2}$. These analyses

354 implied potentially high diversity of formate dehydrogenase in SAOB. In terms of

355 hydrogenase, electron-confurcating hydrogenases HydABC has been found in all novel

356 acetate oxidizers and the known SAOB (except $S$. ultunense) (Figs. 3A and S8; Tables

357 S6 and S7), suggesting such electron confurcation mechanism is universal in SAOB.

358 However, several novel acetate oxidizers had depressed expression of HydABC. We

359 speculate that these populations may have unknown hydrogenase and/or they may

360 transfer formate to other syntrophic populations. Morever, Rnf, NfnAB, PntAB and

361 HydABC were well conserved amongst some novel acetate oxidizers and known SAOB,

362 suggesting that they may serve a core function to SAO.

363 In addition to interspecies electron transfer via hydrogen and formate, DIET has

364 been conceived as a potential mechanism in extracellular electron transfer [54], which

365 depends on electrically conductive type IV pili and outer-surface c-type cytochromes

366 [55]. The putative acetate metabolizers (Only Gemmatimonadetes MAG.ATL080 and

367 Thermoanaerobacteraceae MAG.ATL024) encode a type IV pilin assembly protein

368 (PilC) and a VirB11-like ATPase (PilB), but no genes encoding the structural protein

369 PilA, which is associated with DIET [56], were found (Table S6). A c-type cytochrome

370 was detected in Gemmatimonadetes (MAG.ATL080) and Anaerolineae

371 (MAG.ATL001 and MAG.ATL101), and only MAG.ATL080 and MAG.ATL101 high 
372 expressed this gene (Table S6). Therefore, DIET may play a role in syntrophic acetate

373 degradation, but not the essential role. The roles of DIET in these novel acetate

374 degraders remain unclear but warrant further attention.

\section{Energy-conserving metabolisms in methanogens}

In the archaeal community, Methanosarcina MAG.ATL014 obtained the electrons from intermediate $\mathrm{H}_{2}$ through highly expression of methanophenazine(MP)-reducing hydrogenase (VhoGAC), energy-converting [NiFe] hydrogenase (EchA-F), and $\mathrm{F}_{420}$ reduction hydrogenase (FrhABG) (Figs. 3B and 5; Table S4). The electrons provided by FrhABG were transferred to $\mathrm{F}_{420}$ to produce $\mathrm{F}_{420} \mathrm{H}_{2}$. The electrons carried by $\mathrm{F}_{420} \mathrm{H}_{2}$ were used for two reduction steps (methenyl- $\mathrm{H}_{4} \mathrm{MPT} \rightarrow$ methylene- $\mathrm{H}_{4} \mathrm{MPT} \rightarrow$ methyl$\mathrm{H}_{4} \mathrm{MPT}$ ) in hydrogenotrophic methanogenesis, as well as transferred to MP via a FpoFlacking FpoA-O. Finally, $\mathrm{MPH}_{2}$ reduced by VhoGAC and FpoA-O transferred electrons to CoM-S-S-CoB via heterodisulphide reductase (HdrDE) (Figs. 3B and 5; Table S4). The metabolism yields energy by forming proton motive force via HdrDE [57, 58]. Methanosarcina also highly expressed the heterodisulfide reductase homologous HdrA2B2C2 that oxidize $\mathrm{F}_{420} \mathrm{H}_{2}$ with the reduction of $\mathrm{Fd}_{\mathrm{ox}}$ and $\mathrm{CoB}-\mathrm{S}-\mathrm{S}$ CoM through flavin-based electron bifurcation $[59,60]$. The $\mathrm{H}_{2} / \mathrm{CO}_{2}$-dependent methanogen Methanothermobacter (MAG.ATL045) has genes for $\mathrm{H}_{2}$ oxidation via reverse electron transport (EhaA-T rather than EchA-F), electron bifurcation (MvhADG-HdrABC), and $\mathrm{F}_{420}$ reduction (FrhABG). Nevertheless,

Methanothermobacter did not express all of above genes for $\mathrm{H}_{2}$ /formate oxidation (Figs.

3B and 5; Table S4). Methanomassiliicoccus highly expressed genes for electron- 
394 bifurcating $\mathrm{H}_{2}$ oxidation and a putative ferredoxin: heterodisulfide oxidoreductase

395 complex for electron transduction from $\mathrm{H}_{2}$ to methanol-reducing methanogenesis (via

396 MvhADG, HdrABC, FpoF-lacking Fpo-like, and HdrD) (Fig.3B and 5; Table S4). The

397 high $\mathrm{H}_{2}$ oxidation activity detected in Methanosarcina MAG.ATL014 in ATL was

398 associated with consumption of $\mathrm{H}_{2}$ produced from $\mathrm{SAO}$ and formate oxidation.

399 Moreover, Methanosarcina higher expressed the genes involved in $\mathrm{CO}_{2}$-reducing

400 pathway in ATL compared to PTL and VTL (Tables S3 and S4, [28, 30]). These results

401 implied that Methanosarcina played a multi-trophic functional role in thermophilic

402 chemostats.

403

404 Syntrophic metabolism and energy conservation of acetate-degrading community

405 in propionate-, butyrate-, and isovalerate-fed chemostats

406 As acetate is an important by-product from syntrophic fatty acid degradation (e.g.,

407 propionate, butyrate, and isovalerate), SAOB should be also present in the chemostats

408 fed with these fatty acids. To investigate whether the observed novel SAOB in ATL

409 also play roles in oxidation of other fatty acids, we analyzed the metabolic features of

410 the MAGs involved in the microbial communities in other seven chemostats. Similar

411 with the result in ATL, the previously known SAOB (i.e., T. phaeum, P. lettingae, $S$.

412 ultunense, S. schinkii, and T. acetatoxydans) were not detected in PTL, whereas

413 populations related to the known acetate-oxidizing genus Tepidanaerobacter

414 (MAG.BTL055 and MAG.VTL084) only displayed low activity and did not express

415 acetate oxidizing activity in butyrate- and isovalerate-degrading communities (Fig. S7; 
416 Tables S5 and S6). In propionate-, butyrate- and isovalerate-degrading communities,

417 we identified multiple bacterial populations associated with uncultured Clostridia,

418 Thermoanaerobacteraceae, Anaerolineae, Gemmatimonadetes and

419 Thermodesulfovibrio that encode the reverse WL and glycine-mediated pathways,

420 associated with complementary $\mathrm{NADPH}$ re-oxidation and $\mathrm{H}_{2} /$ formate-generating

421 enzymes (Fig.S7; Tables S5 and S6). Based on the above criteria (See Results and

422 discussion 3.4.1 for details of the settings), among these populations,

423 Thermodesulfovibrio (MAG.PTL017 and MAG.VTL073), Desulfotomaculum

424 (MAG.BTL007), Thermoanaerobacteraceae populations (MAG.VTL038 and

425 MAG.BTL014), Clostridia populations (MAG.PTL141 MAG.BTL065 and

426 MAG.VTL024), and Gemmatimonadetes (MAG.BTL079 and MAG.VTL039) may

427 syntrophically degrade acetate (the former three expressed the reverse Wood-Ljungdahl

428 pathway and the last expressed the Thermotogae-associated pathway; Fig.6; Tables S5

429 and S6). These results confirmed our previous study, in which members of Clostridia,

430 Thermoanaerobacteraceae, Anaerolineae, and Thermodesulfovibrio were labeled with

$431{ }^{13} \mathrm{C}_{2}$-sodium acetate in DNA stable isotope probing assays [23]. Therefore, these

432 microorganisms were potential acetate degrader.

434 Biosynthetic metabolism of acetate oxidizers

435 In our chemostats, the novel SAOB used acetate as the carbon and energy source

436 for producing $\mathrm{H}_{2}$, reducing equivalents (i.e., $\mathrm{NADH}, \mathrm{NADPH}$ and reduced ferredoxin

$\left.437\left[\mathrm{Fd}_{\mathrm{red}}\right]\right)$, and ATP, which provided the cell with energy for biomass biosynthesis. We 
438 further found that these novel acetate degraders encode pathways for converting acetyl-

439 CoA to pyruvate, as well as other important precursors for biosynthesis of sugars, amino

440 acids (AAs) and nucleotides, and pathways for AAs degradation (Tables S8-S10).

441 In complex microbial communities, microbes are frequently observed to interact

442 other individuals by exchanging the above mentioned metabolites as public goods [61,

443 62], we thus set out to test whether this is also the case in our novel SAOB. Strikingly,

444 we found that no single SAOB contains all the genes encoding the synthesis of an entire

445 suite of amino acids (AAs) (Fig. S9 and Table S8), suggesting that the exchange of the

446 essential AAs (one typical set of public goods reported previously [63, 64]) is common

447 between these novel SAOB in thermophilic fatty acid-degrading community. Further

448 analyses indicated that acetate degraders tended to lose/ lowly express the AA

449 biosynthetic pathway with higher energy cost (Fig. S9 and Table S8). In addition, the

450 populations which closely related to each other possessed similar capabilities for AA

451 biosynthesis. The Clostridia-related acetate metabolizers (MAG.ATL044,

452 MAG.PTL141, MAG.BTL065 and MAG.VTL024), which displayed the dominant

453 activity in individual chemostat and proposed glycine-mediated acetate oxidation

454 pathway, only synthesized three AAs (i.e., glutamate, glycine, and serine) (Fig. S9 and

455 Table S8). In comparison with the most active acetate degraders (MAG.ATL044,

456 MAG.PTL141, MAG.BTL065 and MAG.VTL024), other acetate degraders have genes

457 for synthesizing more AAs, whereas they had depressed expression of biosynthesis for

458 the majority of AAs (Fig. S9 and Table S8). According to the Black Queen Hypothesis,

459 when an individual loses an energy-expensive function, it becomes a 'beneficiary', who 
460

462

scavenges the public goods, such as AAs, from other individuals (helpers) for survival $[65,66]$. The 'beneficiary' strain will expand in the community until the production of public goods, such as AAs, is just sufficient to support the balanced community. AA biosynthesis is an energy-consuming process, and therefore, the acetate metabolizers can invest more energy to their metabolism on acetate oxidation rather than biosynthesis. These results suggest that the metabolic exchange of public goods between SAOB and other members plays a significant role on maintaining high efficiency of acetate metabolism during the AD process.

\section{The prevalence of the novel SAOB across diverse thermophilic AD communities}

The novel acetate degraders from uncultured lineages in this study (members of Clostridia, Thermoanaerobacteraceae, Anaerolineae, and Gemmatimonadetes) from ATL, PTL, BTL and VTL were distantly related to any isolated species (Fig. S10). Moreover, these novel acetate oxidizers were closely related ( $\geqslant 97 \%$ similarity; Fig.

S11) to uncultured populations detected in thermophilic anaerobic digesters feeding with a wide diversity of substrates (e.g., sole carbon source [67, 68], binary carbon source [69], municipal waste [70, 71], agricultural waste $[72,73]$ and industrial waste $[74,75])$. Therefore, the novel syntrophic lineages revealed in the present study are the universal and probably core species that play a critical role in thermophilic methanogenic process in thermophilic anaerobic digestion.

\section{Conclusion}



oxidizers still requires further effortful cultivation-based studies. Managing the and energy shortage.

\section{Materials and Methods}

\section{Operation of thermophilic anaerobic chemostats}

Eight thermophilic $\left(55^{\circ} \mathrm{C}\right)$ anaerobic chemostats (Fig. S12) were constructed

500 using continuous stirred tank reactors (CSTRs), each with a working volume of $1.8 \mathrm{~L}$.

501 The seed sludge for inoculating acetate- and propionate-degrading chemostats was

502 obtained from a thermophilic anaerobic digester treating kitchen waste (Sichuan

503 Province, China), and the seed sludge for inoculating butyrate- and isovalerate- 
504 degrading chemostats was from a swine manure treatment plant (Sichuan Province,

505 China) (Table S1). The seed sludge was rinsed with the washing solution (synthetic

506 wastewater without carbon sources) thrice under anaerobic condition, diluted to $1.8 \mathrm{~L}$,

507 and then inoculated into each chemostat.

508 The thermophilic chemostats were fed with synthetic wastewater containing 509 acetate, propionate, butyrate, or isovalerate as the sole carbon source, respectively (total

510 organic carbon $\left.[\mathrm{TOC}]=8000 \mathrm{mg} \cdot \mathrm{L}^{-1}\right)($ Table $\mathrm{S} 1)$. The synthetic wastewater contains $0.3 \mathrm{~g} / \mathrm{L} \mathrm{KH}_{2} \mathrm{PO}_{4}, 4.0 \mathrm{~g} / \mathrm{L} \mathrm{KHCO}_{3}, 1.0 \mathrm{~g} / \mathrm{L} \mathrm{NH} 4 \mathrm{Cl}, 0.6 \mathrm{~g} / \mathrm{L} \mathrm{NaCl}, 0.82 \mathrm{~g} / \mathrm{L} \mathrm{MgCl}_{2} \cdot 6 \mathrm{H}_{2} \mathrm{O}$,

514 solution. $5.46 \mathrm{~g}$ sodium acetate and $16.0 \mathrm{~g}$ acetic acid were added for acetate synthetic

515 wastewater, $4.27 \mathrm{~g}$ sodium propionate and $13.16 \mathrm{~g}$ propionic acid were added for 516 propionate synthetic wastewater, $14.67 \mathrm{~g}$ butyric acid and $1.33 \mathrm{~g} \mathrm{NaOH}$ were added for 517 butyrate synthetic wastewater, $13.60 \mathrm{~g}$ isovalerate acid and $1.07 \mathrm{~g} \mathrm{NaOH}$ were added 518 for isovalerate synthetic wastewater.

519 Briefly, the thermophilic chemostats were incubated in thermostat-controlled 520 water-baths (TR-2A, ASONE, Osaka, Japan). Broth in each chemostat was thoroughly 521 mixed using a magnetic stirrer at 200-300 rpm. Synthetic wastewater was supplied to 522 the chemostats by continuous feeding under an atmosphere of $\mathrm{N}_{2}$, and the effluent over 523 flowed automatically via a U-type tube. Biogas was collected with a gas holder. Initially, 524 two replicated chemostats were performed for each carbon source, so a total of eight 525 chemostats were operated. The eight thermophilic chemostats were initially operated at 
526 a dilution rate of $0.01 \mathrm{~d}^{-1}$ and then increased to $0.025 \mathrm{~d}^{-1}$ (hydraulic retention time [HRT]

$527=40 \mathrm{~d}$ ), after a period of operation at a dilution rate of $0.025 \mathrm{~d}^{-1}$, dilution rates of four

528 chemostats were increased to $0.05 \mathrm{~d}^{-1}$ (hydraulic retention time [HRT] $=20 \mathrm{~d}$ ). For

529 simplicity, we used A (acetate), P (propionate), B (butyrate), and V (isovalerate) to

530 denote four different carbon sources used in these chemostats; L was used to indicate

531 the lower dilution rate $\left(0.025 \mathrm{~d}^{-1}\right)$, whereas $\mathrm{H}$ indicated the higher dilution rate $\left(0.05 \mathrm{~d}^{-}\right.$

$532{ }^{1}$ ). Therefore, the eight chemostats were named as ATL, PTL, BTL, VTL, ATH, PTH,

533 BTH, and VTH, respectively (Table S1).

534 Broth was sampled every week for fluorescence microscopic observation and

535 physicochemical analyses of $\mathrm{pH}$, suspended solids (SS), volatile suspended solids

536 (VSS), TOC, as well as volatile fatty acids (VFAs) using the same protocols described

537 previously [28]. In addition, the methane and $\mathrm{H}_{2}$ contents in biogas were determined by

538 a gas chromatograph (GC-2014C, Shimadzu, Kyoto, Japan). During the steady

539 operation period, biomass collected from broth was used for DNA and RNA extraction.

541 DNA and RNA extraction, 16S rRNA gene PCR, sequencing, and data processing

542 Sludge was collected from $40 \mathrm{~mL}$ broth from each chemostat (ATL, day 286; ATH,

543 day 258; PTL, day 283; PTH, day 400; BTL, day 284; BTH, day 398; VTL, day 300;

544 VTH day 360 ) by centrifugation at $13000 \times \mathrm{g}$ at $4^{\circ} \mathrm{C}$ for $10 \mathrm{~min}$. The sludge was rinsed

545 thrice with sterile phosphate buffer saline (PBS) (10 mM, pH 7.5). Total DNA and RNA

546 (duplicates for each sample) were extracted via cyltrimethyl ammonium bromide

547 (CTAB) method [76]. Total RNA was reverse transcribed using PrimeScript ${ }^{\mathrm{TM}}$ RT 
548 reagent Kit with gDNA Eraser (Perfect Real Time) according to the manufacturer's

549 protocol (Takara, Kusatsu, Japan). DNA and cDNA samples were subjected to $16 \mathrm{~S}$

550 rRNA gene amplicon sequencing. The 16S rRNA genes of both bacteria and archaea

551 were amplified through PCR using universal primers 515F $\left(5^{\prime}-\right.$

552 GTGCCAGCMGCCGCGGTAA-3') and 909R (5'-CCCCGYCAATTCMTTTRAGT-

553 3') targeting the V4-V5 hypervariable regions. The 16S rRNA gene amplicon

554 sequencing was performed on an Illumina MiSeq platform (Illumina, San Diego, CA,

555 USA) according to the standard protocols by Majorbio Bio-Pharm Technology Co. Ltd.

556 (Shanghai, China). The data processing was conducted using the protocol as previously

557 reported [23].

558

559 Metagenomic and metatranscriptomic sequencing, as well as the associated

560 bioinformatics analyses

561 Sludge samples for metagenomic sequencing were collected on different dates

562 from ATL (day 306 and 307), PTL (day 223, 293 and 318), BTL (day 251 and 252),

563 VTL (day 295 and 296). Similarly, sludge samples for metatranscriptomic sequencing

564 were collected on two different dates from ATL (day 302 and 305), PTL (day 223, and

565 293), BTL (day 247 and 249), VTL (day 291 and 293). Total DNA and RNA were

566 extracted using CTAB method [76]. Metagenomic DNA was sequenced on an Illumina

567 HiSeq 2000 platform (Illumina). The paired-end reads $(2 \times 150 \mathrm{bp})$ were trimmed via

568 Trimmomatic v0.36 [77] with a quality cutoff of 30, sliding window of $6 \mathrm{bp}$ and

569 minimum length cutoff of $100 \mathrm{bp}$. The clean reads from different metagenomes of the

570 same chemostat were co-assembled via SPAdes v.3.5.0 [78], binned through MetaBAT

571 [79], and checked for completeness and contamination using CheckM [80]. The 
572 completeness was calculated based on the number of expected marker genes present in

573 MAGs, while the contamination based on the number of expected marker genes present

574 in multiple copies. Genes were annotated using Prokka [81] and manual curation was

575 performed as described previously [30]. Phylogenomic trees were built with

576 PhyloPhlAn v0.99 ("-u" option) [82], and the tree was edited using iTOL [83].

581 (Illumina) with the standard protocol. The libraries were sequenced on an Illumina

582 HiSeq2000 sequencer. The paired-end $(2 \times 150 \mathrm{bp})$ metatranscriptomic reads were

583 trimmed as DNA-trimming step described above and mapped to MAGs using the

$$
\text { BBMap with the parameters as: } \operatorname{minid}=1 \quad(\mathrm{v} 35.85 \text {; }
$$

585 http://sourceforge.net/projects/bbmap/). The gene expression levels of functional genes

586 from each MAG were calculated as reads per kilobase transcript per million reads 587 mapped to the MAG (RPKM) averaged from duplicate samples. The RPKM was further 588 normalized to the median gene expression level in the heat map illustration for each bin 589 (RPKM-NM) averaged from duplicate samples [33]. Raw sequence data reported in 590 this paper have been deposited (PRJCA005330) in the Genome Sequence Archive in 591 the BIG Data Center, Chinese Academy of Sciences under accession codes CRA004311

592 for 16S rRNA gene, metagenomics and metatranscriptomics sequencing data that are 593 publicly accessible at http://bigd.big.ac.cn/gsa. 


\section{Acknowledgements}

597 This study was funded by the National Natural Science Foundation of China (No.

598 51678378) and the Ministry of Science and Technology of China (No.

599 2016YFE0127700).

600

601 References

602 1. Pind PF, Angelidaki I, Ahring BK. Dynamics of the anaerobic process: effects

603 of volatile fatty acids. Biotechnol Bioeng. 2003, 82:791-801.

604 2. Mountfort DO, Asher RA. Changes in proportions of acetate and carbon dioxide used as methane precursors during the anaerobic digestion of bovine waste.

606 Appl Environ Microbiol. 1978, 35:648-54.

607 3. Mackie RI, Bryant MP. Metabolic activity of fatty acid-oxidizing bacteria and 608 the contribution of acetate, propionate, butyrate, and $\mathrm{CO}_{2}$ to methanogenesis in cattle waste at 40 and $60^{\circ} \mathrm{C}$. Appl Environ Microbiol. 1981, 41:1363-1373.

610 4. Hattori S. Syntrophic acetate-oxidizing microbes in methanogenic 611 environments. Microbes Environ. 2008, 23:118-27.

612 5. Ferry J. Methane from acetate. J Bacteriol. 1992, 174:5489-5495.

613 6. Kato S, Watanabe K. Ecological and evolutionary interactions in syntrophic 614 methanogenic consortia. Microbes Environ. 2010, 25:145-151.

615 7. Sun L, Müller B, Westerholm M, Schnürer A. Syntrophic acetate oxidation in industrial CSTR biogas digesters. J Biotechnol. 2014, 171:39-44.

617 8. Zhu X, Kougias PG, Treu L, Campanaro S, Angelidaki I. Microbial community 

thermophilic conditions. Appl Microbiol Biotechnol. 2017, 101:1313-1322.

620 9. Shigematsu T, Tang YQ, Kawaguchi H, Ninomiya K, Kijima J, Kobayashi T, Morimura S, Kida K. Effect of dilution rate on structure of a mesophilic acetatedegrading methanogenic community during continuous cultivation. J Biosci Bioeng. 2003, 96:547-558.

10. Hattori S, Kamagata Y, Hanada S, Shoun H. Thermacetogenium phaeum gen. nov., sp. nov., a strictly anaerobic, thermophilic, syntrophic acetate-oxidizing bacterium. Int J Syst Evol Microbiol. 2000, 50:1601-1609.

11. Westerholm M, Roos S, Schnürer A. Syntrophaceticus schinkii gen. nov., sp. nov., an anaerobic, syntrophic acetate-oxidizing bacterium isolated from a mesophilic anaerobic filter. FEMS Microbiol Lett. 2010, 309:100-104.

12. Westerholm M, Roos S, Schnürer A. Tepidanaerobacter acetatoxydans sp. nov., an anaerobic, syntrophic acetate-oxidizing bacterium isolated from two ammonium-enriched mesophilic methanogenic processes. Syst Appl Microbiol. 2011, 34:260-266. analysis and whole transcriptome profiling of the mesophilic syntrophic acetate oxidising bacterium Syntrophaceticus schinkii. PLoS One. 2016, 11:e0166520.

638 14. Oehler D, Poehlein A, Leimbach A, Müller N, Daniel R, Gottschalk G, Schink B. Genome-guided analysis of physiological and morphological traits of the 
642 15. Balk M, Weijma J, Stams AJM. Thermotoga lettingae sp. nov., a novel thermophilic, methanol-degrading bacterium isolated from a thermophilic anaerobic reactor. Int J Syst Evol Microbiol. 2002, 52:1361-1368.

645 16. Schnurer A, Schink B, Svensson BH. Clostridium ultunense sp. nov., a mesophilic bacterium oxidizing acetate in syntrophic association with a hydrogenotrophic methanogenic bacterium. Int J Syst Bacteriol. 1996, 46:11451152.

649 17. Nobu MK, Narihiro T, Rinke C, Kamagata Y, Tringe SG, Woyke T, Liu WT. Microbial dark matter ecogenomics reveals complex synergistic networks in a methanogenic bioreactor. ISME J. 2015, 9:1710-1722.

652 18. Ahring BK, Westermann P. Kinetics of butyrate, acetate, and hydrogen metabolism in a thermophilic, anaerobic, butyrate-degrading triculture. Appl

655 19. Narihiro T, Terada T, Ohashi A, Kamagata Y, Nakamura K, Sekiguchi Y. Quantitative detection of previously characterized syntrophic bacteria in anaerobic wastewater treatment systems by sequence-specific rRNA cleavage method. Water Res. 2012, 46:2167-2175.

659 20. Treu L, Kougias PG, Campanaro S, Bassani I, Angelidaki I. Deeper insight into the structure of the anaerobic digestion microbial community; the biogas microbiome database is expanded with 157 new genomes. Bioresour Technol. 
662

663

664

665

666

667

668

669

670

671

672

673

674

675

676

677

678

679

680

681

2016, 216:260-266.

21. Vanwonterghem I, Jensen PD, Rabaey K, Tyson GW. Genome-centric resolution of microbial diversity, metabolism and interactions in anaerobic digestion. Environ Microbiol. 2016, 18:3144-3158.

22. Mosbæk F, Kjeldal H, Mulat DG, Albertsen M, Ward AJ, Feilberg A, Nielsen JL. Identification of syntrophic acetate-oxidizing bacteria in anaerobic digesters by combined protein-based stable isotope probing and metagenomics. ISME J. 2016, 10:2405-18.

23. Zheng D, Wang HZ, Gou M, Nobu MK, Narihiro T, Hu B, Nie Y, Tang YQ. Identification of novel potential acetate-oxidizing bacteria in thermophilic methanogenic chemostats by DNA stable isotope probing. Appl Microbiol Biotechnol. 2019, 103:8631-8645.

24. Ito T, Yoshiguchi K, Ariesyady HD, Okabe S. Identification of a novel acetateutilizing bacterium belonging to Synergistes group 4 in anaerobic digester sludge. ISME J. 2011, 5:1844-1856.

25. Stams AJ, Plugge CM. Electron transfer in syntrophic communities of anaerobic bacteria and archaea. Nat Rev Microbiol. 2009, 7:568-577.

26. Shen L, Zhao Q, Wu X, Li X, Li Q, Wang Y. Interspecies electron transfer in syntrophic methanogenic consortia: from cultures to bioreactors. Renew Sust Energ Rev. 2016, 54:1358-1367.

27. Manzoor S, Schnürer A, Bongcam-Rudloff E, Müller B. Genome-guided analysis of Clostridium ultunense and comparative genomics reveal different 
strategies for acetate oxidation and energy conservation in syntrophic acetateoxidising bacteria. Genes. 2018, 9 .

28. Chen YT, Zeng Y, Wang HZ, Zheng D, Kamagata Y, Narihiro T, Nobu MK, Tang YQ. Different interspecies electron transfer patterns during mesophilic and thermophilic syntrophic propionate degradation in chemostats. Microb Ecol.

29. Hidalgo-Ahumada CAP, Nobu MK, Narihiro T, Tamaki H, Liu WT, Kamagata behaviour of Pelotomaculum schinkii driving syntrophic propionate catabolism. MK, Tang YQ. Novel syntrophic isovalerate-degrading bacteria and their energetic cooperation with methanogens in methanogenic chemostats. Environ Sci Technol. 2020. 54(15):9618-9628. doi: 10.1021/acs.est.0c01840. ethanol to perform direct interspecies electron transfer for syntrophic

701 32. Zhao Z, Li Y, Yu Q, Zhang Y. Ferroferric oxide triggered possible direct interspecies electron transfer between Syntrophomonas and Methanosaeta to enhance waste activated sludge anaerobic digestion. Bioresour Technol. 2018,

705 33. Nobu MK, Narihiro T, Liu M, Kuroda K, Mei R, Liu WT. Thermodynamically 
diverse syntrophic aromatic compound catabolism. Environ Microbiol. 2017.

707

708

709

710

711

712 19(11): 4576-4586.

34. Zhu X, Campanaro S, Treu L, Seshadri R, Ivanova N, Kougias PG, Kyrpides N, Angelidaki I. Metabolic dependencies govern microbial syntrophies during methanogenesis in an anaerobic digestion ecosystem. Microbiome. 2020;8(1):22. doi: 10.1186/s40168-019-0780-9.

35. Lackner N, Hintersonnleitner A, Wagner AO, Illmer P. Hydrogenotrophic Methanogenesis and Autotrophic Growth of Methanosarcina thermophila. Archaea. 2018, 2018:1-7.

36. Hovey R, Lentes S, Ehrenreich A, Salmon K, Saba K, Gottschalk G, Gunsalus RP, Deppenmeier U. DNA microarray analysis of Methanosarcina mazei Gö1 reveals adaptation to different methanogenic substrates. Mol Genet Genomics. 2005, 273:225-239.

37. Li Q, Li L, Rejtar T, Karger BL, Ferry JG. Proteome of Methanosarcina acetivorans Part II: comparison of protein levels in acetate- and methanolgrown cells. J Proteome Res. 2005, 4:129-135.

38. Heine-Dobbernack E, Schoberth SM, Sahm H. Relationship of intracellular coenzyme $F(420)$ content to growth and metabolic activity of Methanobacterium bryantii and Methanosarcina barkeri. Appl Environ Microbiol.1988, 54:454-459.

39. Ahring BK, Westermann P, Mah RA. Hydrogen inhibition of acetate metabolism and kinetics of hydrogen consumption by Methanosarcina 
40. Hao L, Lü F, Mazéas L, Desmond-Le Quéméner E, Madigou C, Guenne A, Shao incubations shows a partial resistance of acetoclastic methanogenesis catalyzed by Methanosarcina to sudden increase of ammonia level. Water Res. 2015, 69:90-99.

41. Dong M, Gonzalez TD, Klems MM, Steinberg LM, Chen W, Papoutsakis ET, Bahnson BJ. In vitro methanol production from methyl coenzyme $\mathrm{M}$ using the Methanosarcina barkeri MtaABC protein complex. Biotechnol Prog. 2017, 33: 1243-1249.

42. Hattori S, Galushko AS, Kamagata Y, Schink B. Operation of the CO dehydrogenase/acetyl coenzyme A pathway in both acetate oxidation and acetate formation by the syntrophically acetate-oxidizing bacterium Thermacetogenium phaeum. J Bacteriol. 2005, 187:3471-6.

43. Buckel W, Thauer RK. Energy conservation via electron bifurcating ferredoxin reduction and proton/ $\mathrm{Na}(+)$ translocating ferredoxin oxidation. Biochim Biophys Acta. 2013, 1827:94-113.

745 44. McInerney MJ, Rohlin L, Mouttaki H, Kim U, Krupp RS, Rios-Hernandez L, genome of Syntrophus aciditrophicus: life at the thermodynamic limit of microbial growth. Proc Natl Acad Sci U S A. 2007, 104:7600-7605.

45. Sieber JR, McInerney MJ, Gunsalus RP. Genomic insights into syntrophy: the 
paradigm for anaerobic metabolic cooperation. Annu Rev Microbiol. 2012, $66: 429-52$.

752 46. Biegel E, Schmidt S, González JM, Müller V. Biochemistry, evolution and physiological function of the Rnf complex, a novel ion-motive electron transport complex in prokaryotes. Cell Mol Life Sci. 2010, 68:613-634.

47. Wang S, Huang H, Moll J, Thauer RK. NADP ${ }^{+}$reduction with reduced ferredoxin and $\mathrm{NADP}^{+}$reduction with $\mathrm{NADH}$ are coupled via an electronbifurcating enzyme complex in Clostridium kluyveri. J Bacteriol. 2010, 192:5115-23.

48. Sauer U, Canonaco F, Heri S, Perrenoud A, Fischer E. The soluble and membrane-bound transhydrogenases UdhA and PntAB have divergent functions in NADPH metabolism of Escherichia coli. J Biol Chem. 2004, 279:6613-9.

49. Shi A, Zhu X, Lu J, Zhang X, Ma Y. Activating transhydrogenase and NAD kinase in combination for improving isobutanol production. Metab Eng. 2013, $16: 1-10$.

766 50. Nobu MK, Narihiro T, Hideyuki T, Qiu YL, Sekiguchi Y, Woyke T, Goodwin L, 767 Davenport KW, Kamagata Y, Liu WT. The genome of Syntrophorhabdus aromaticivorans strain UI provides new insights for syntrophic aromatic compound metabolism and electron flow. Environ Microbiol. 2015.

771 51. Nobu MK, Narihiro T, Mei R, Kamagata Y, Lee PKH, Lee PH, McInerney MJ, 

doi: 10.1186/s40168-020-00885-y.

775 52. Dolfing J, Jiang B, Henstra AM, Stams AJ, Plugge CM. Syntrophic growth on formate: a new microbial niche in anoxic environments. Appl Environ Microbiol. 2008, 74:6126-6131.

53. Lv XM, Yang M, Dai LR, Tu B, Chang C, Huang Y, Deng Y, Lawson PA, Zhang

54. Reguera G, McCarthy KD, Mehta T, Nicoll JS, Tuominen MT, Lovley DR. 1098-1101.

55. Malvankar NS, Lovley DR. Microbial nanowires for bioenergy applications. Curr Opin Biotechnol. 2014, 27:88-95.

788 56. Walker DJF, Nevin KP, Holmes DE, Rotaru AE, Ward JE, Woodard TL, Zhu J, pili demonstrate that common hydrogen-donating syntrophs can have a direct electron transfer option. ISME J. 2020, 14:837-846. conservation of Methanosarcina mazei. FEBS J. 2010, 277:3396-3403. 
794 58. Welte C, Deppenmeier U. Bioenergetics and anaerobic respiratory chains of

795

796

797

798

799

800

801

802

803

804

805

806

807

808

809

810

aceticlastic methanogens. Biochim Biophys Acta. 2014, 1837:1130-1147.

59. Yan Z, Wang M, Ferry JG. A Ferredoxin- and $\mathrm{F}_{420} \mathrm{H}_{2}$-dependent, electronbifurcating, heterodisulfide reductase with homologs in the domains bacteria and archaea. mBio. 2017. 8(1): e2285-16. doi: 10.1128/mBio.02285-16.

60. Holmes DE, Rotaru AE, Ueki T, Shrestha PM, Ferry JG, Lovley DR. Electron and proton flux for carbon dioxide reduction in Methanosarcina barkeri during direct interspecies electron transfer. Front Microbiol. 2018. 9: 3109. doi: 10.3389/fmicb.2018.03109.

61. West SA, Griffin AS, Gardner A, Diggle SP. Social evolution theory for microorganisms. Nat Rev Microbiol. 2006, 4:597-607.

62. Liu Y-F, Galzerani DD, Mbadinga SM, Zaramela LS, Gu J-D, Mu B-Z, Zengler K. Metabolic capability and in situ activity of microorganisms in an oil reservoir. Microbiome. 2018 Jan 5;6(1):5. doi: 10.1186/s40168-017-0392-1.

63. Mee MT, Collins JJ, Church GM, Wang HH. Syntrophic exchange in synthetic microbial communities. Proc Natl Acad Sci U S A. 2014, 111:E2149-E2156.

64. Zomorrodi AR, Segrè D. Genome-driven evolutionary game theory helps understand the rise of metabolic interdependencies in microbial communities. Nat Commun. 2017, 8:1563. doi: 10.1038/s41467-017-01407-5.

65. Morris JJ, Lenski RE, Zinser ER. The Black Queen Hypothesis: evolution of dependencies through adaptive gene loss. mBio. 2012, 3:e00036-12. doi: 10.1128/mBio.00036-12. 
816 66. Wang M, Liu X, Nie Y, Wu XL. Selfishness driving reductive evolution shapes interdependent patterns in spatially structured microbial communities. ISME J. 2020. doi: 10.1038/s41396-020-00858-x.

819 67. Tang YQ, Matsui T, Morimura S, Wu XL, Kida K. Effect of temperature on microbial community of a glucose-degrading methanogenic consortium under hyperthermophilic chemostat cultivation. J Biosci Bioeng. 2008, 106:180-187.

68. Cheng L, He Q, Ding C, Dai LR, Li Q, Zhang H. Novel bacterial groups dominate in a thermophilic methanogenic hexadecane-degrading consortium. FEMS Microbiol Ecol. 2013, 85:568-577.

69. Ueno, Y. and Tatara, M. Microbial population in a thermophilic packed-bed reactor for methanogenesis from volatile fatty acids. Enzyme and Microbial

70. Tang YQ, Shigematsu T, Ikbal, Morimura S, Kida K. The effects of microaeration on the phylogenetic diversity of microorganisms in a thermophilic

831 71. Goberna M, Insam H, Franke-Whittle IH. Effect of biowaste sludge maturation on the diversity of thermophilic bacteria and archaea in an anaerobic reactor.

72. Weiss A, Jérôme V, Burghardt D, Likke L, Peiffer S, Hofstetter EM, Gabler R, Freitag R. Investigation of factors influencing biogas production in a large-scale 
838 73. Lachnit T, Meske D, Wahl M, Harder T, Schmitz R. Epibacterial community patterns on marine macroalgae are host-specific but temporally variable. Environ Microbiol. 2011, 13:655-665.

841 74. Wang TT, Sun ZY, Huang YL, Tan L, Tang YQ, Kida K. Biogas production from distilled grain waste by thermophilic dry anaerobic digestion: pretreatment of feedstock and dynamics of microbial community. Appl Biochem Biotechnol.

75. Hillion ML, Moscoviz R, Trably E, Leblanc Y, Bernet N, Torrijos M, Escudié R. Co-ensiling as a new technique for long-term storage of agro-industrial waste with low sugar content prior to anaerobic digestion. Waste Manag. 2018,

76. Griffiths RI, Whiteley AS, O'Donnell AG, Bailey MJ. Rapid method for coextraction of DNA and RNA from natural environments for analysis of ribosomal DNA- and rRNA-based microbial community composition. Appl sequence data. Bioinformatics. 2014, 30:2114-2120.

855 78. Bankevich A, Nurk S, Antipov D, Gurevich AA, Dvorkin M, Kulikov AS, Lesin VM, Nikolenko SI, Pham S, Prjibelski AD, Pyshkin AV, Sirotkin AV, Vyahhi N, Tesler G, Alekseyev MA, Pevzner PA. SPAdes: a new genome assembly 
860 79. Kang DD, Froula J, Egan R, Wang Z. MetaBAT, an efficient tool for accurately reconstructing single genomes from complex microbial communities. PeerJ.

862 2015, 3:e1165.

863 80. Parks DH, Imelfort M, Skennerton CT, Hugenholtz P, Tyson GW. CheckM: assessing the quality of microbial genomes recovered from isolates, single cells, and metagenomes. Genome Res. 2015, 25:1043-1055.

866 81. Torsten S: Prokka: rapid prokaryotic genome annotation. Bioinformatics 2014, 30:2068-2069.

868 82. Segata N, Börnigen D, Morgan XC, Huttenhower C. PhyloPhlAn is a new method for improved phylogenetic and taxonomic placement of microbes. Nat Commun. 2013, 4:2304-2304.

871 83. Letunic I, Bork P. Interactive tree of life (iTOL) v3: an online tool for the display and annotation of phylogenetic and other trees. Nucleic Acids Res. 2016, 44:W242-245. 
874 Table 1. Operational performance of mesophilic and thermophilic chemostats during the steady operation period ${ }^{\mathrm{a}}$.

\begin{tabular}{|c|c|c|c|c|c|c|c|c|}
\hline Chemostat name & ATL & ATH & PTL & PTH & BTL & BTH & VTL & VTH \\
\hline Carbon source & Acetate & Acetate & Propionate & Propionate & Butyrate & Butyrate & Isovalerate & Isovalerate \\
\hline Dilution rate $\left(\right.$ day $\left.^{-1}\right)$ & 0.025 & 0.05 & 0.025 & 0.05 & 0.025 & 0.05 & 0.025 & 0.05 \\
\hline HRT (day) & 40 & 20 & 40 & 20 & 40 & 20 & 40 & 20 \\
\hline Inflow concentration $\left(\mathrm{mg} \cdot \mathrm{L}^{-1}\right)$ & 20000 & 20000 & 16444 & 16444 & 14667 & 14667 & 13600 & 13600 \\
\hline $\begin{array}{l}\text { Gas production rate }\left(\mathrm{mL} \cdot \mathrm{L}^{-1} \cdot \mathrm{d}^{-}\right. \\
\left.{ }^{1}\right)\end{array}$ & $115 \pm 22$ & $294 \pm 67$ & $103 \pm 17$ & $383 \pm 43$ & $155 \pm 28$ & $396 \pm 35$ & $143 \pm 37$ & $365 \pm 18$ \\
\hline $\mathrm{CH}_{4}$ content $(\%)$ & $58 \pm 4$ & $60 \pm 5$ & $62 \pm 2$ & $63 \pm 3$ & $66 \pm 2$ & $73 \pm 4$ & $67 \pm 4$ & $76 \pm 6$ \\
\hline $\mathrm{H}_{2}$ partial pressure $(\mathrm{Pa})$ & $0.8 \pm 0.4$ & $1.4 \pm 0.6$ & $2.9 \pm 1.2$ & $3.1 \pm 1.3$ & $2.3 \pm 1.4$ & $2.9 \pm 1.3$ & $2.0 \pm 1.2$ & $2.5 \pm 0.9$ \\
\hline $\mathrm{pH}$ & $8.04 \pm 0.14$ & $7.85 \pm 0.14$ & $7.95 \pm 0.14$ & $7.78 \pm 0.14$ & $7.78 \pm 0.08$ & $7.63 \pm 0.11$ & $7.84 \pm 0.14$ & $7.66 \pm 0.10$ \\
\hline $\mathrm{TOC}\left(\mathrm{mg} \cdot \mathrm{L}^{-1}\right)$ & $139 \pm 83$ & $132 \pm 78$ & $84 \pm 49$ & $118 \pm 46$ & $87 \pm 74$ & $123 \pm 91$ & $84 \pm 49$ & $114 \pm 44$ \\
\hline Formate $\left(\mathrm{mg} \cdot \mathrm{L}^{-1}\right)^{\mathrm{b}}$ & ND & ND & ND & ND & ND & ND & ND & ND \\
\hline Acetate $\left(\mathrm{mg} \cdot \mathrm{L}^{-1}\right)$ & $11 \pm 22$ & $12 \pm 35$ & $6 \pm 8$ & $2 \pm 4$ & $31 \pm 47$ & $27 \pm 69$ & $23 \pm 53$ & $20 \pm 20$ \\
\hline Propionate $\left(\mathrm{mg} \cdot \mathrm{L}^{-1}\right)$ & 0 & 0 & $11 \pm 13$ & $15 \pm 48$ & $\sim 1.0$ & $\sim 1.0$ & $\sim 1.0$ & $\sim 1.0$ \\
\hline Butyrate $\left(\mathrm{mg} \cdot \mathrm{L}^{-1}\right)$ & 0 & 0 & 0 & 0 & $\sim 1.0$ & $\sim 1.0$ & $\sim 1.0$ & $\sim 1.0$ \\
\hline Valerate $\left(\mathrm{mg} \cdot \mathrm{L}^{-1}\right)$ & 0 & 0 & 0 & 0 & 0 & 0 & $\sim 1.0$ & $\sim 1.0$ \\
\hline Iso-valerate $\left(\mathrm{mg} \cdot \mathrm{L}^{-1}\right)$ & 0 & 0 & 0 & 0 & 0 & 0 & $\sim 1.0$ & $\sim 1.0$ \\
\hline $\mathrm{SS}\left(\mathrm{g} \cdot \mathrm{L}^{-1}\right)$ & $0.421 \pm 0.08$ & $0.543 \pm 0.14$ & $0.468 \pm 0.11$ & $0.68 \pm 0.07$ & $1.43 \pm 0.49$ & $1.44 \pm 0.38$ & $1.35 \pm 0.44$ & $1.38 \pm 0.25$ \\
\hline $\operatorname{VSS}\left(g \cdot L^{-1}\right)$ & $0.308 \pm 0.07$ & $0.392 \pm 0.11$ & $0.352 \pm 0.10$ & $0.513 \pm 0.07$ & $0.62 \pm 0.21$ & $0.65 \pm 0.18$ & $0.57 \pm 0.21$ & $0.67 \pm 0.19$ \\
\hline
\end{tabular}

${ }^{\mathrm{a}} \mathrm{HRT}$, hydraulic retention time; TOC, total organic carbon; VSS, volatile suspended solid; ND, not detected. The operational parameters (e.g., pH, gas production

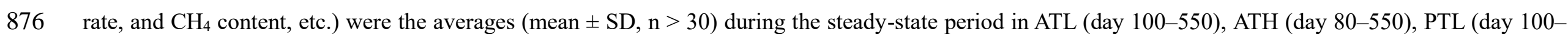

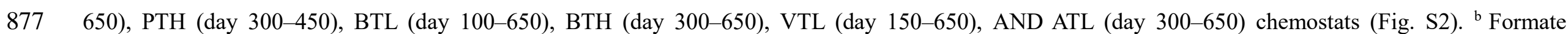

878 concentration was below the detective limit $\left(10 \mathrm{mg} \mathrm{L}^{-1}\right)$ of the high-performance liquid chromatography. 


\section{$879 \quad$ Figure Legends}

880 Fig. 1. Relative abundance of bacterial genera based on 16S rRNA gene amplicon

881 sequencing in the thermophilic chemostats (DNA level).

882 Fig. 2. Metabolic pathways of acetate oxidation and methanogenesis in thermophilic 883 acetate-degrading chemostat (A), and distribution of catabolic pathways among the 884 studied contributors (B). For each syntroph and methanogen, we show presence 885 (indicated by filled circle) of genes encoding pathways for acetate catabolism and 886 methanogenesis. Enzyme abbreviations are as follows: Ack, acetate kinase; Pta, 887 phosphate acetyltransferase; Acs, acetyl-CoA synthetase; CODH complex, acetyl CoA 888 synthetase complex; AcsE, methyltetrahydrofolate:corrinoid/iron-sulfur protein 889 methyltransferase; MetF, methylenetetrahydrofolate reductase; FolD, 890 methylenetetrahydrofolate dehydrogenase/cyclohydrolase; Fhs, formate-891 tetrahydrofolate ligase; Fdh, formate dehydrogenase. Grd, glycine reductase; Por, 892 pyruvate dehydrogenase; PflD, pyruvate-formate lyase; Sda, serine dehydratase; GlyA, 893 glycine hydroxymethyltransferase; GcvPA, glycine dehydrogenase subunit A; GcvPB, 894 glycine dehydrogenase subunit B, GcvT, glycine cleavage system T protein; GcvH, 895 glycine cleavage system H protein; Dld, dihydrolipoyl dehydrogenase. Fmd, 896 formylmethanofuran dehydrogenase; Ftr, formylmethanofuran897 tetrahydromethanopterin $\mathrm{N}$-formyltransferase; Mch, methenyltetrahydromethanopterin 898 cyclohydrolase; Mtd, methylenetetrahydromethanopterin dehydrogenase; Mer, $\mathrm{F}_{420^{-}}$ 899 dependent 5,10-methenyltetrahydromethanopterisn reductase; Cdh, acetyl-CoA 900 decarbonylase/synthase complex; Mta, [methyl-Co(III) methanol-specificcorrinoid 901 protein]:CoM methyltransferase; Mtb, [methyl-Co(III) dimethylamine902 specificcorrinoid protein]:CoM methyltransferase; Mtm, [methyl-Co(III) 903 monomethylamine-specificcorrinoid protein]:CoM methyltransferase ; Mtr, 904 tetrahydromethanopterin S-methyltransferase; Mcr, methyl-CoM reductase. CHO905 MF, formyl-methanofuran; CHO-H4MPT, formyl-tetrahydromethanopterin; $906 \mathrm{CH} \equiv \mathrm{H}_{4} \mathrm{MPT}$, methenyl-tetrahydromethanopterin; $\mathrm{CH}_{2}=\mathrm{H}_{4} \mathrm{MPT}$, methylene907 tetrahydromethanopterin; $\mathrm{CH}_{3}-\mathrm{H}_{4} \mathrm{MPT}$, methyl-tetrahydromethanopterin; $\mathrm{CH}_{3}-\mathrm{S}-\mathrm{CoM}$, 908 methyl-coenzyme M; HS-CoM, coenzyme M; HS-CoB, coenzyme B; CoB-S-S-CoM, 909 mixed disulphide of $\mathrm{CoM}$ and $\mathrm{CoB}$. Enzyme abbreviations and their corresponding 910 genes are elaborated in Supporting Information Tables S3 and S5.

911 Fig. 3. Gene expression level for acetate oxidation, $\mathrm{H}_{2} /$ formate metabolism, and 912 electron transfer genes in syntrophs which may syntrophically degrade acetate 
913 and methanogens (B) from thermophilic acetate-degrading chemostat. For each

914 metagenome-assembled genome (MAG), the percentages of the metatranscriptomic

915 (MT) reads mapped to the MAG out of the metatranscriptomics mapped to all MAGs

916 (both Bacteria and Archaea) are shown. The gene expression levels are calculated as

917 reads per kilobase of transcript per million reads mapped to individual MAG (RPKM)

918 normalized to the median gene expression for the corresponding MAG (RPKM-NM)

919 averaged from duplicate samples. Pathways containing genes with RPKM-NM greater

920 than the octile and quartile are marked (filled and open dots, respectively). Enzyme

921 abbreviations and their corresponding genes are elaborated in Supporting Information

922 Tables S3-S6.

923 Fig. 4. Phylogenetic analyses of metagenome-assembled genomes (MAGs) of 924 syntrophs in thermophilic acetate-degrading chemostat. The corresponding abundance 925 of MAGs are estimated from their metagenomic coverage calculated as the percentage 926 of metagenomics (MG) reads mapped to each MAG relative to the total reads mapped 927 to all bacterial and archaeal MAGs. The estimated activity of MAGs in acetate928 degrading chemostat are shown as the percentage of metatranscriptomic (MT) reads 929 mapped to each MAG relative to total reads mapped to all bacterial and archaeal MAGs 930 (T, totoal MT reads; T1, MT reads of sampling time point 1; T2, MT reads of sampling 931 time point 2).

932 Fig. 5. Overview of the metabolism of syntrophs and methanogens from thermophilic 933 acetate-degrading communities. Hydrogenase, formate dehydrogenases and energy 934 conservation pathways are abbreviated as shown in Supporting Information Tables S3935 S6.

936 Fig. 6. Gene expression level for acetate oxidation, $\mathrm{H}_{2} /$ formate metabolism, and 937 electron transfer genes in syntrophs which may syntrophically degrade acetate from 938 thermophilic chemostats. For each MAG, the percentages of the metatranscriptomic 939 (MT) reads mapped to the MAG out of the metatranscriptomics mapped to all MAGs 940 (both Bacteria and Archaea) are shown. The gene expression levels are calculated as 941 reads per kilobase of transcript per million reads mapped to individual MAG (RPKM) 942 normalized to the median gene expression for the corresponding MAG (RPKM-NM) 943 averaged from duplicate samples. Pathways containing genes with RPKM-NM greater 944 than the octile and quartile are marked (filled and open dots, respectively). Enzyme 945 abbreviations and their corresponding genes are elaborated in Supporting Information 946 Tables S5-S6. 
bioRxiv preprint doi: https://doi.org/10.1101/2021.07.06.451242; this version posted July 6, 2021. The copyright holder for this preprint (which was not certified by peer review) is the author/funder, who has granted bioRxiv a license to display the preprint in perpetuity. It is made available under aCC-BY-NC-ND 4.0 International license.

\section{$947 \quad$ Fig. 1.}

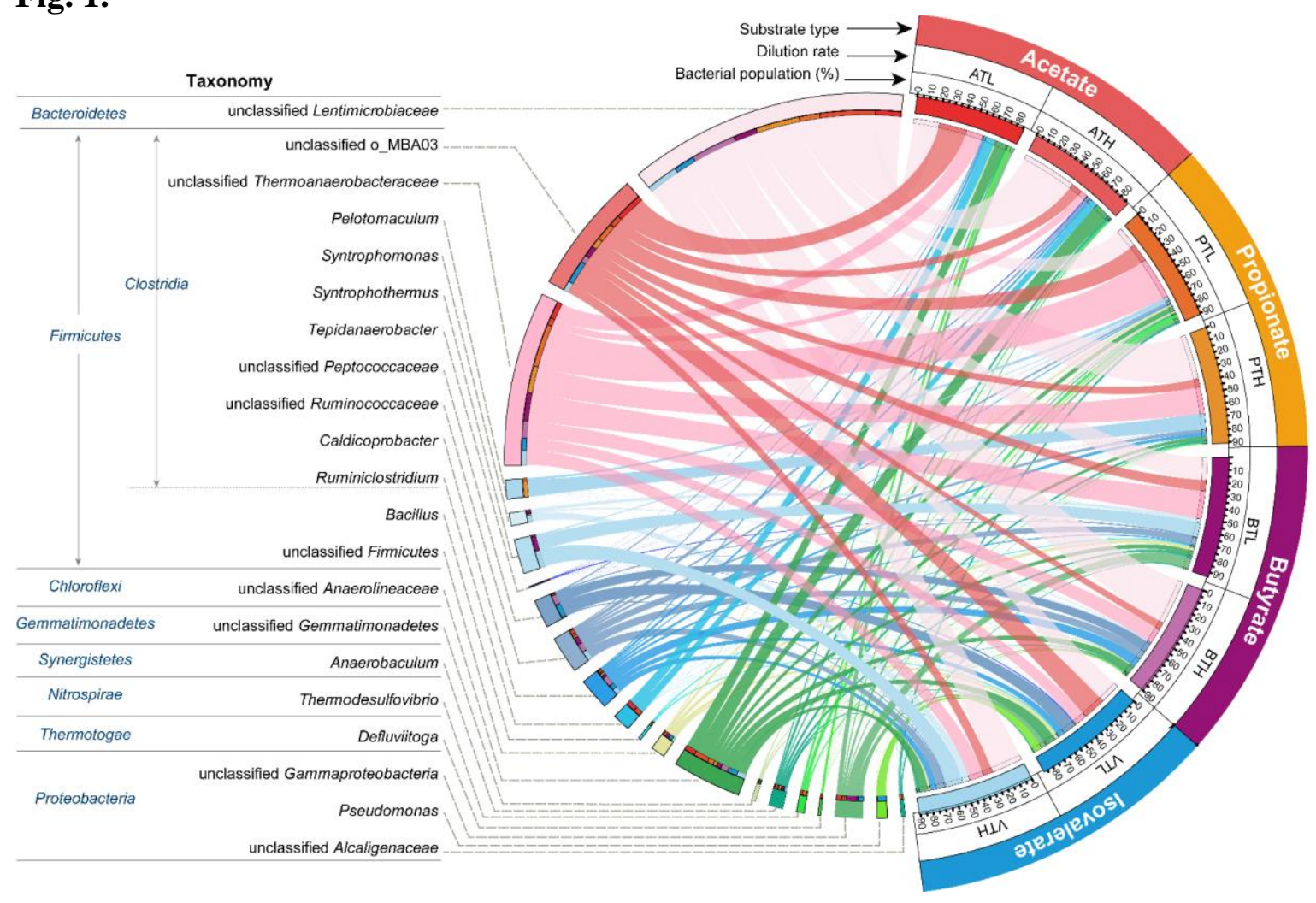


bioRxiv preprint doi: https://doi.org/10.1101/2021.07.06.451242; this version posted July 6, 2021. The copyright holder for this preprint (which was not certified by peer review) is the author/funder, who has granted bioRxiv a license to display the preprint in perpetuity. It is made available under aCC-BY-NC-ND 4.0 International license.

949 Fig. 2.

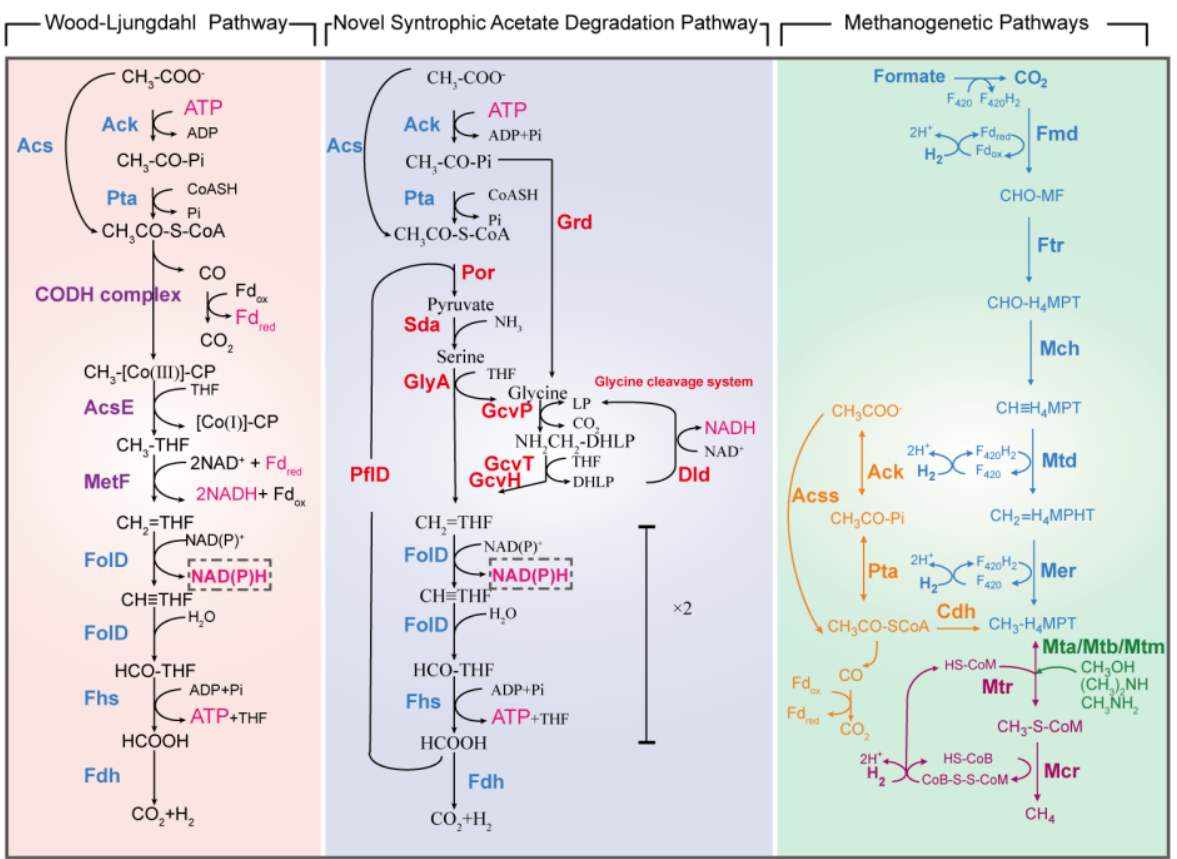

B

Acetate Oxidation

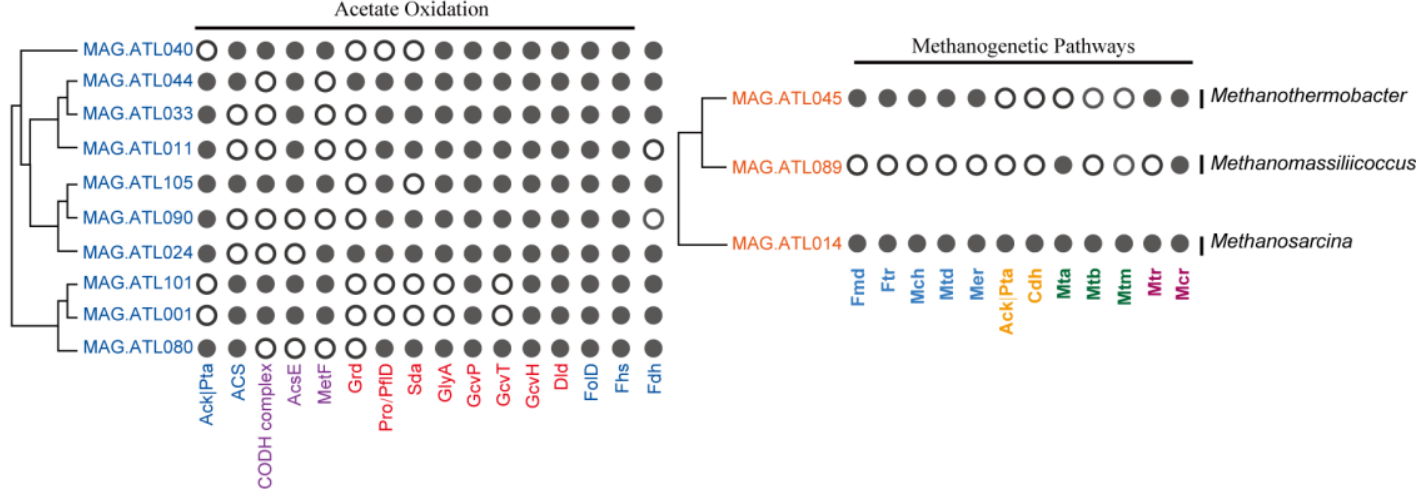


bioRxiv preprint doi: https://doi.org/10.1101/2021.07.06.451242; this version posted July 6, 2021. The copyright holder for this preprint (which was not certified by peer review) is the author/funder, who has granted bioRxiv a license to display the preprint in perpetuity. It is made available under aCC-BY-NC-ND 4.0 International license.

$951 \quad$ Fig. 3.

A MT-predicted activity(\%)

Clostridia

Thermoanaerobacteraceae

Anaerolineae

Gemmatimonadetes

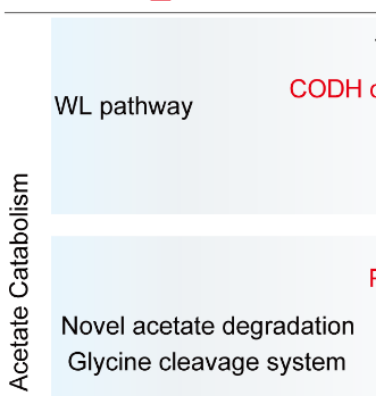

Ack|Pta

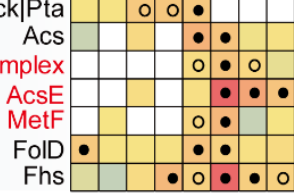

Por|P

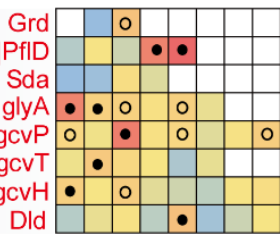

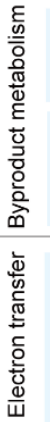

Formate dehydrogenase

FdhA-HydBC

FdhH

Hydrogenase

HydABC

HndABCD

HybABCO HoxEFUHY

952
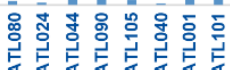

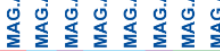
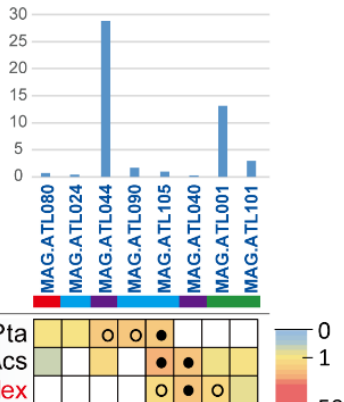

尚

त) Hydrogenotrophic

을 Acetotrophic

Methylotrophic

売

B

T-predicted activity(\%)

Methanosarcina

Methanothermobacter

Methanomassiliicoccus

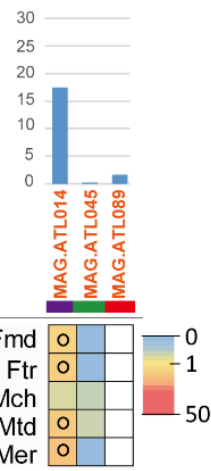

Ack|Pta

Cdh $\bullet$

MtbABC

MtbA-MtmBC

\begin{tabular}{r|l|l|l|} 
Mtr & $\bullet$ & & \\
Mcr & $\bullet$ & $\bullet$
\end{tabular}

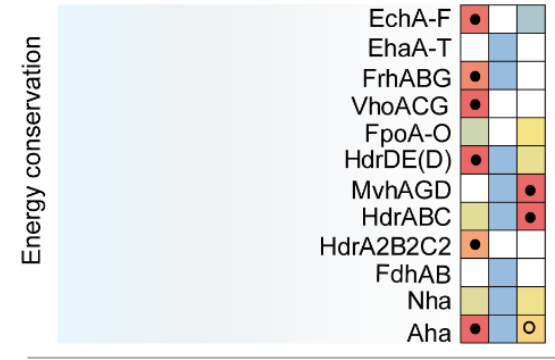


bioRxiv preprint doi: https://doi org/10.1101/2021.07.06.451242. this version posted July 6. 2021. The copyright holder for this preprint (which was not certified by peer review) is the author/funder, who has granted bioRxiv a license to display the preprint in perpetuity. It is made available under aCC-BY-NC-ND 4.0 International license.

Fig. 4.

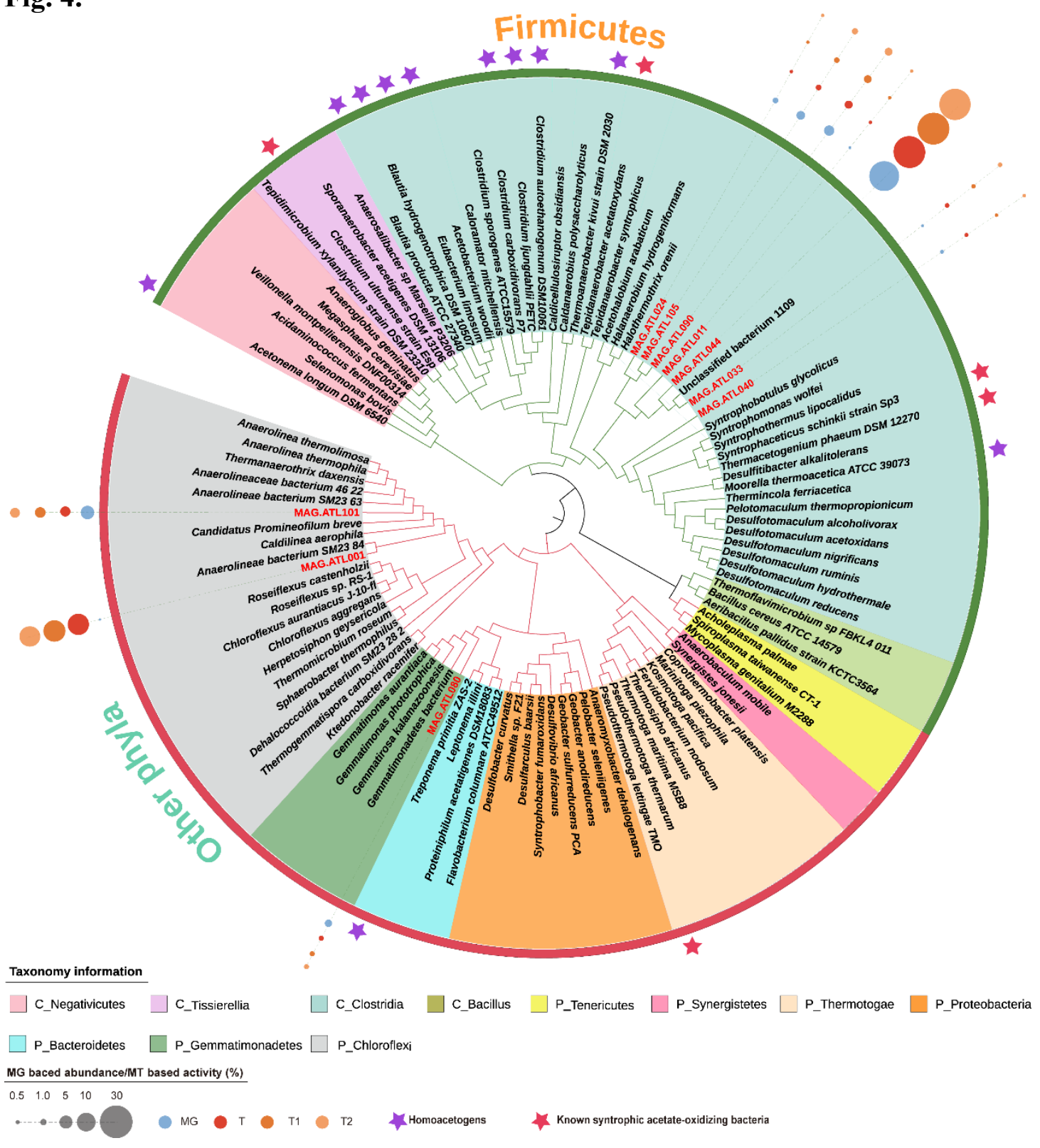


bioRxiv preprint doi: https://doi.org/10.1101/2021.07.06.451242; this version posted July 6, 2021. The copyright holder for this preprint (which was not certified by peer review) is the author/funder, who has granted bioRxiv a license to display the preprint in perpetuity. It is made available under aCC-BY-NC-ND 4.0 International license.

\section{$955 \quad$ Fig. 5}

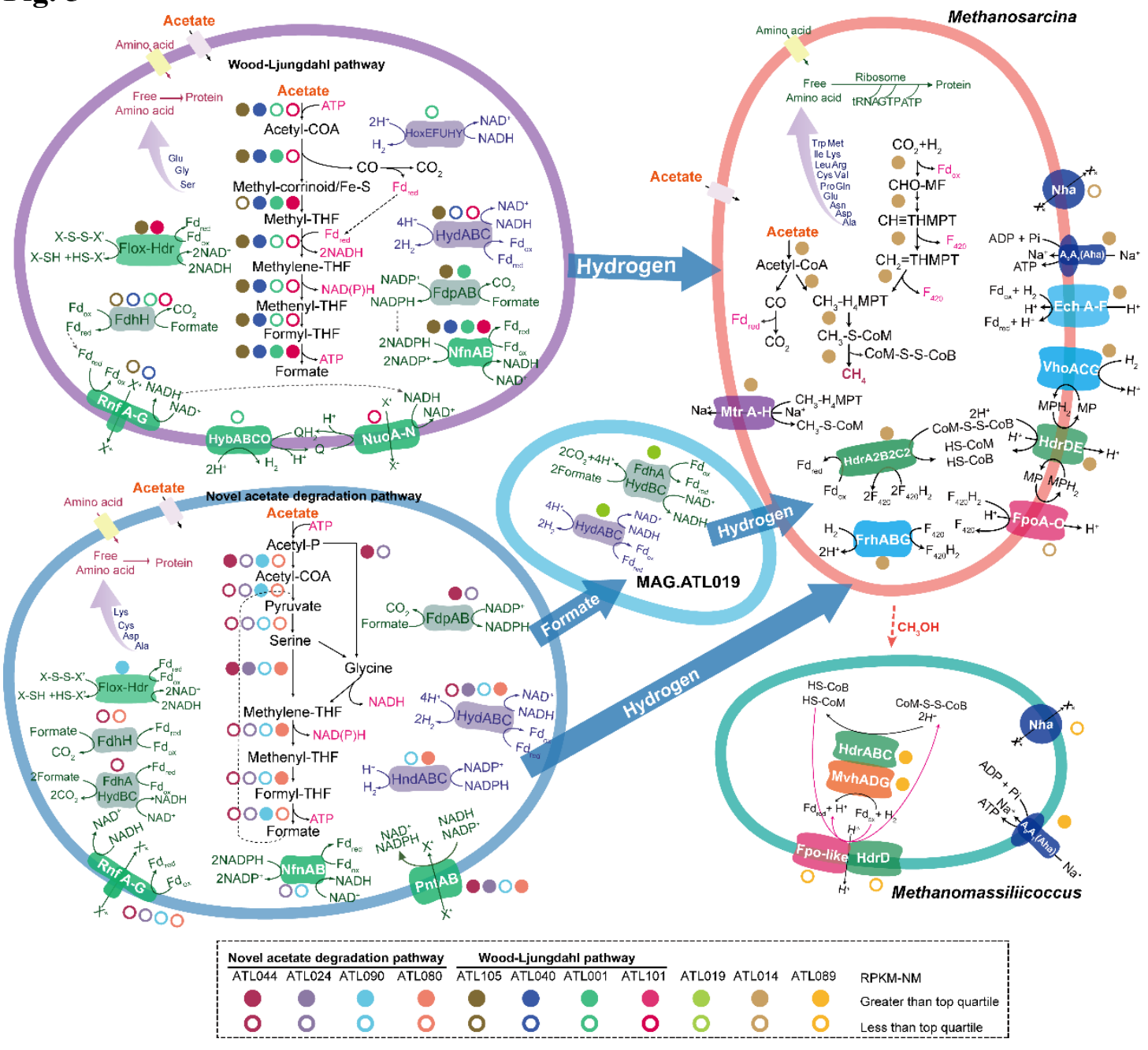


bioRxiv preprint doi: https://doi.org/10 1101/2021.07.06.451242; this version posted July 6 . 2021. The copyriaht holder for this preprint (which was not certified by peer review) is the author/funder, who has granted bioRxiv a license to display the preprint in perpetuity. It is made available under aCC-BY-NC-ND 4.0 International license.

Fig. 6

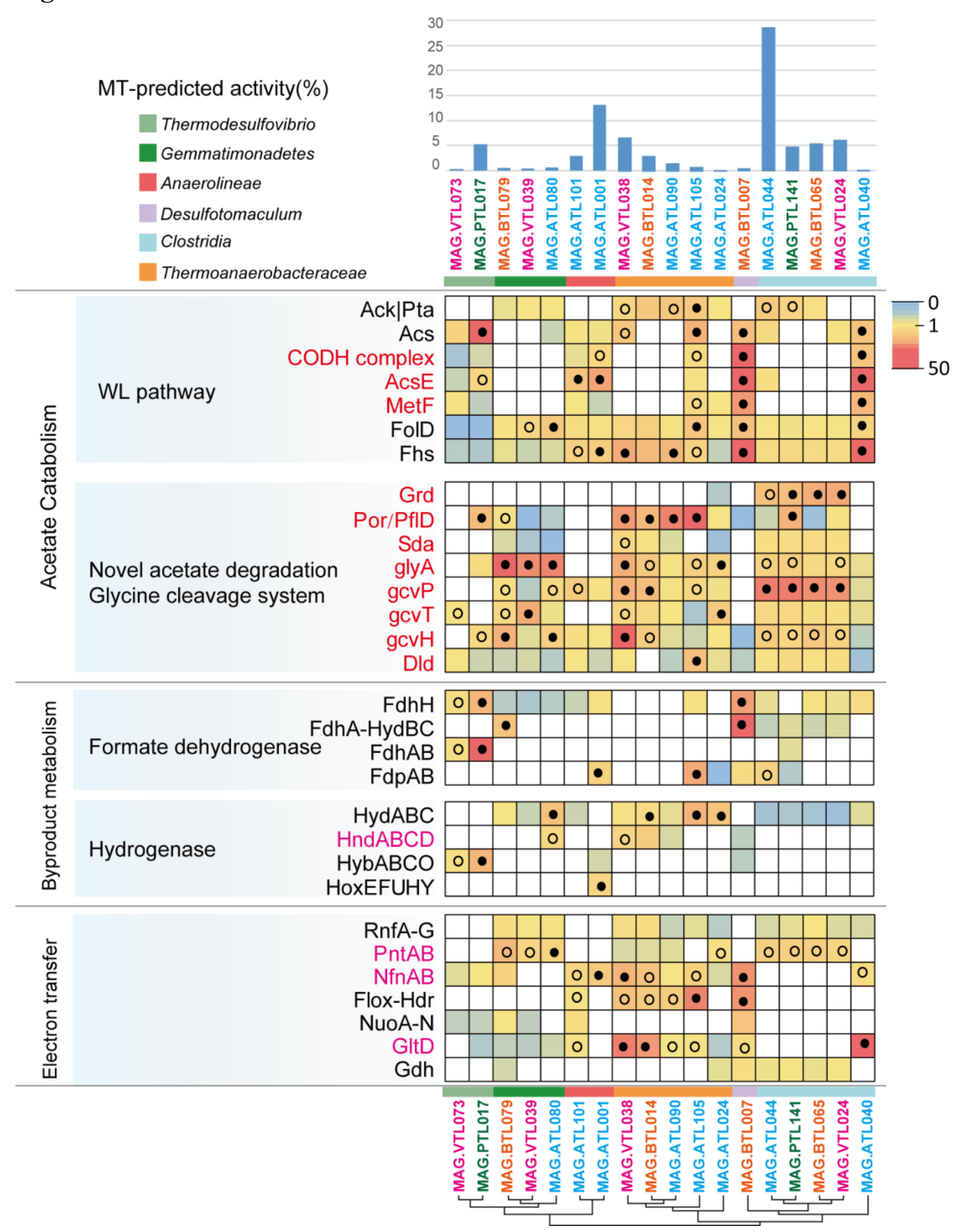

年

0

